\title{
Nuclear export of Far1p in response to pheromones requires the export receptor Msn5p/Ste21p
}

\author{
Marc Blondel, ${ }^{1}$ Paula M. Alepuz, ${ }^{2}$ Linda S. Huang, ${ }^{3}$ Shai Shaham, ${ }^{3}$ Gustav Ammerer, ${ }^{2}$ \\ and Matthias Peter ${ }^{1,4}$ \begin{abstract}
of Biochemistry and Molecular Cell Biology, University of Vienna and Ludwig Boltzmann-Forschungsstelle für Biochemie, 1030 Vienna, Austria; ${ }^{3}$ Department of Biochemistry and Biophysics, University of California, San
\end{abstract} \\ ${ }^{1}$ Swiss Institute for Experimental Cancer Research (ISREC), 1066 Epalinges/VD, Switzerland; ${ }^{2}$ Vienna Biocenter, Institute \\ Francisco, San Francisco, California 94143-0448 USA
}

Far1p is a bifunctional protein that is required to arrest the cell cycle and to establish cell polarity during yeast mating. Far1p is localized predominantly in the nucleus but accumulates in the cytoplasm in cells exposed to pheromones. Here we show that Far1p functions in both subcellular compartments: nuclear Far1p is required to arrest the cell cycle, whereas cytoplasmic Far1p is involved in the establishment of cell polarity. The subcellular localization of Far1p is regulated by two mechanisms: (1) Far1p contains a functional bipartite nuclear localization signal (NLS), and (2) Far1p is exported from the nucleus by Msn5p/Ste21p, a member of the exportin family. Cells deleted for Msn5p/Ste21p failed to export Far1p in response to pheromones, whereas overexpression of Msn5p/Ste21p was sufficient to accumulate Far1p in the cytoplasm in the absence of pheromones. Msn5p/Ste21p was localized in the nucleus and interacted with Far1p in a manner dependent on GTP-bound Gsp1p. Two-hybrid analysis identified a small fragment within Far1p that is necessary and sufficient for binding to Msn5p/Ste21p, and is also required to export Far1p in vivo. Finally, similar to $\Delta m s n 5 / s t e 21$ strains, cells expressing a mutant Far1p, which can no longer be exported, exhibit a mating defect, but are able to arrest their cell cycle in response to pheromones. Taken together, our results suggest that nuclear export of Far1p by Msn5p/Ste21p coordinates the two separable functions of Far1p during mating.

[Key Words: Export; cell cycle; mating; Msn5p/Ste21p; NLS]

Received February 11, 1999; revised version accepted July 6, 1999.

In eukaryotic cells, a double membrane system known as the nuclear envelope separates the nucleus from the cytoplasm, thus forming two distinct subcellular compartments. The localization of proteins to either the nucleus or the cytoplasm can confer regulation of their function (Görlich and Mattaj 1996; Nigg 1997). In many instances this regulation is imposed by the cell cycle stage or by activation of a signal transduction pathway in response to extracellular signals. For example, the transcription factor Swi5p is nuclear only during the $G_{1}$ phase of the cell cycle (Moll et al. 1991), whereas multiple mitogen-activated protein kinases (MAPKs) translocate into the nucleus in response to growth factors (Feldherr and Akin 1994).

Yeast-mating pheromones regulate the subcellular localization of Farlp; Farlp is nuclear in the absence of pheromones but is found predominantly in the cytoplasm in cells treated with pheromones (Butty et al. 1998). Pheromones trigger a MAPK signal transduction

${ }^{4}$ Corresponding author.

E-MAIL Matthias.Peter@esrec.unel.ch; FAX (41) 21-652-6933 pathway, which results in transcriptional activation of many genes, cell cycle arrest, and changes in cell polarity and morphology (Sprague and Thorner 1992; Leberer et al. 1997). These responses are initiated by binding of pheromones to a seven-transmembrane receptor, which is coupled to a heterotrimeric G protein. G $\beta \gamma$ then transduces the signal through its effectors Ste5p and Ste20p to a MAPK cascade composed of Ste11p, Ste7p, and Fus3p (Herskowitz 1995; Leeuw et al. 1998). Fus3p is thought to phosphorylate the transcriptional repressors Dig1p and Dig2p resulting in activation of the transcription factor Ste12p (Cook et al. 1996; Pi et al. 1997; Tedford et al. 1997) and regulates the activity of Farlp, which is required to arrest the cell cycle presumably by inhibiting cyclin-dependent kinases (Peter and Herskowitz 1994; Gartner et al. 1998). Farlp also functions as an adaptor that targets cytoplasmic polarity establishment proteins to the heterotrimeric G protein (Butty et al. 1998; Nern and Arkowitz 1999).

We are interested in understanding how the subcellular localization of Farlp is regulated in response to pheromones. Subcellular localization of proteins can be controlled by regulating import into or export from the 
nucleus. Two types of targeting signals mediate nuclear transport of proteins: nuclear localization signal (NLS) sequences promote nuclear import and generally consist of a cluster of basic amino acids (Kalderon et al. 1984; Dingwall and Laskey 1991). Second, nuclear export signal (NES) sequences promote export of proteins from the nucleus to the cytoplasm. A small leucine-rich sequence was the first NES identified, and was shown to be necessary and sufficient to export the human immunodeficient virus (HIV) Rev protein and protein kinase inhibitor (PKI), an inhibitor of cAMP-dependent protein kinase A (Nakielny and Dreyfuss 1997). Targeting signals are recognized by a family of soluble receptors, which are heterodimers consisting of importin $\alpha$ and importin $\beta$. The complex translocates with the cargo into or out of the nucleus and disassembles in the new compartment (Nigg 1997). In several cases, binding of import or export receptors to the targeting signal of the cargo is regulated by phosphorylation (Moll et al. 1991; Sidorova et al. 1995; Beals et al. 1997; DeVit et al. 1997; Kaffmann et al. 1998a).

Both genetic and biochemical experiments demonstrate a crucial role of the small GTPase Ran (or Gsp1p in yeast) in both nuclear import and export (Koepp and Silver 1996). Ran is found in the nucleus and cytoplasm, but because the regulators of Ran are localized differentially, the nucleus is thought to contain Ran predominantly in its GTP form, whereas Ran-GDP is predominantly cytoplasmic. This asymmetric distribution of GDP- and GTP-Ran controls assembly and disassembly of transport complexes. Binding of Ran-GTP to importin $\beta$ family members involved in export promotes interaction with the NES-containing cargo in the nucleoplasm, whereas in the cytoplasm binding of importin $\beta$ members involved in import allows translocation of NLS-containing proteins into the nucleus. In the nucleus, exchange of Ran-GDP to Ran-GTP by the exchange factor Rcc1 (or Rnalp in yeast) facilitates release of the cargo from importin $\beta$. Thus, the nucleotide state of Ran serves as a marker for nuclear and cytoplasmic compartments and imparts directionality to transport processes (Görlich et al. 1996; Izauralde et al. 1997).

Searches of the yeast genome database revealed at least 13 proteins with significant homology to importin $\beta$, and several family members have now been shown to function as import or export receptors. The uncharacterized receptors are thought to define additional import and export pathways. A major challenge is to identify targets of the multiple import and export receptors and to understand their role in controlling the subcellular localization of the target proteins in response to extracellular signals.

Here we show that the subcellular localization of Farlp is regulated by two pathways: (1) A bipartite NLS in the amino terminus of Farlp is necessary for efficient import into the nucleus in a cell cycle- and pheromoneindependent manner; and (2) we have identified Msn5p/ Ste21p as a nuclear export receptor for Far1p. Msn5p/ Ste21p was localized in the nucleus and was required to export Far1p in response to pheromones. Msn5p/Ste21p bound Farlp through a novel NES sequence in a manner dependent on the Ran homolog Gsplp. Accumulation of Farlp in the cytoplasm required activation of the pheromone response pathway but not transcriptional activation of Msn5p/Ste21p, suggesting that post-translational mechanisms regulate relocalization of Farlp in response to pheromones. Finally, our results suggest distinct roles for nuclear and cytoplasmic Farlp during yeast mating and may serve as a paradigm for how cell cycle arrest and polarity establishment are coordinated.

\section{Results \\ Far1p contains a functional bipartite NLS}

To identify sequences within Farlp required for nuclear localization, we determined the subcellular localization of fusions between portions of Farlp and the green fluorescent protein (GFP). We found that the amino-terminal domain of Farlp was required for nuclear localization; deletion of 50 amino-terminal amino acids resulted in a truncated Farl protein, which was found predominantly in the cytoplasm (Fig. 1A). Importantly, a fusion protein between this amino-terminal domain of Farlp and GFP was found in the nucleus (Fig. 1C), demonstrating that these 50 amino acids of Farlp are not only required but also sufficient for nuclear localization. Closer examination of the sequence revealed two potential bipartite NLSs located between amino acids 11 and 30 (nls1) and 38 and 48 (nls2) of Far1p (Fig. 1B). To address the functional importance of these putative NLS sequences for the localization of Farlp, we mutated the lysine residues 29 and 30 (Far1p-K29A/K30A; nls1) and 41 and 42 (Farlp-R41A/K42A; nls2) to alanine residues. Whereas Farlp-nls2 was still localized predominantly in the nucleus, Farlp-nls1 was found largely in the cytoplasm, even in the absence of pheromones, demonstrating that NLS1 comprises a functional NLS (Fig. 1A). However, some remaining nuclear staining of Farlp-nls1 was still visible, suggesting that NLS2 may contribute to efficient nuclear localization of Farlp. Consistent with this notion, a Farlp mutant protein that has both putative NLS sequences inactivated (Farlp-nls1/nls2) was almost exclusively cytoplasmic (Fig. 1A). NLS1 and NLS2 may function as two separate bipartite NLS or they may be part of the same NLS sequence. Taken together, these results demonstrate that Farlp contains a functional bipartite NLS sequence in the amino-terminal 50 amino acids; NLS1 plays a major role, whereas NLS2 contributes to nuclear localization of Farlp to a minor extent (see also below).

\section{Msn5p/Ste21p functions as an exportin for Far1p}

Next, we examined whether Farlp might be exported from the nucleus in response to pheromones. Nuclear export is mediated by exportins, which bind to target proteins and export them in an ATP- and Ran-dependent 

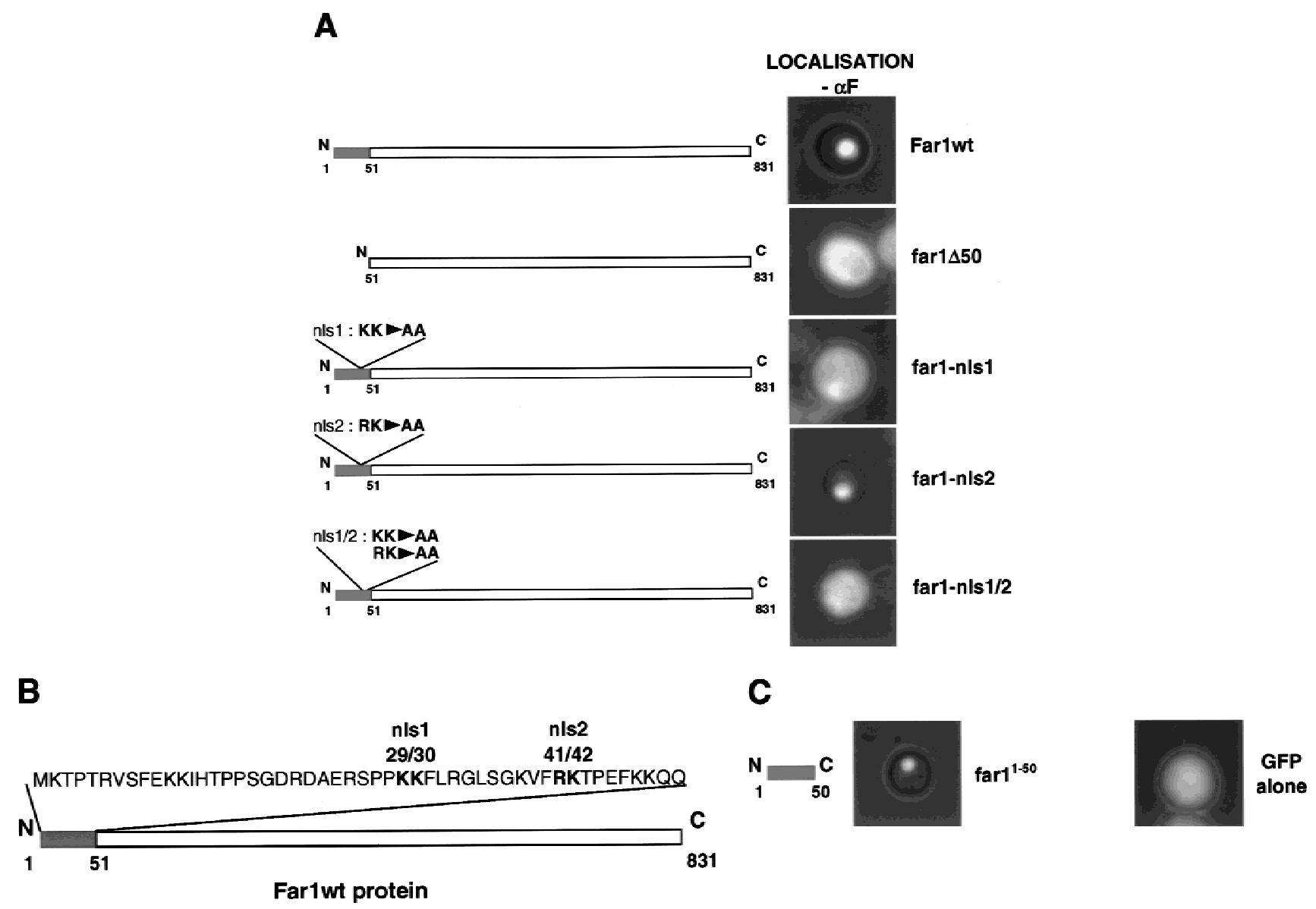

Figure 1. Farlp contains a functional NLS in the amino terminus. $(A)$ Wild-type or various Farlp mutant proteins were expressed as fusions to GFP from the inducible GAL promoter and visualized by fluorescence microscopy. The introduced mutations are indicated schematically of left. Photographs show GFP fluorescence superimposed with phase contrast. (B) Schematic representation of Farlp and the 50 amino-terminal amino acids that are required for nuclear localization of Farlp. The mutated basic amino acids that are part of a bipartite nuclear localization signal are highlighted in bold. $(C)$ The 50 amino-terminal amino acids of Farlp are sufficient to localize GFP in the nucleus. GFP fused to the 50 amino-terminal amino acids of Farlp (far $1^{1-50}$; left) or GFP alone (right) were expressed in cells and visualized as described above.

manner (Göhrlich and Mattaj 1996). Because cells lacking MSN5/STE21 exhibit reduced mating efficiency (Akada et al. 1996) and Msn5p/Ste21p displays significant sequence homology with exportins (Weis 1998) and interacts with Ran-GTP (Göhrlich et al. 1997), we tested whether Msn5p/Ste21p may be involved in localization of Farlp. Interestingly, we observed that Farlp remained exclusively nuclear in $\Delta m s n 5 / s t e 21$ cells treated with pheromones (Fig. 2A), suggesting that Msn5p/Ste21p is involved in exporting Farlp. Strikingly, although Farlpnls1 was predominantly cytoplasmic in wild-type cells, it accumulated in the nucleus of cells deleted for STE21/ MSN5 (Fig. 2B). Both defects were fully corrected by a plasmid expressing endogenous levels of Msn5p/Ste21p (Fig. 2B, right; data not shown), confirming that the defects are caused by lack of Msn5p/Ste21p. We conclude that Msn5p/Ste21p is required for cytoplasmic localization of Farlp in response to pheromones. These results further indicate that Farlp is very dynamic and shuttles between the nucleus and the cytoplasm even in the absence of pheromones.
To test whether expression of Msn5p/Ste21p is sufficient to accumulate Farlp in the cytoplasm, we overexpressed Msn5p/Ste21p from the inducible GAL promoter. Strikingly, Farlp relocalized efficiently under these conditions and was found predominantly in the cytoplasm (Fig. 3A). Addition of $\alpha$-factor further increased the cytoplasmic pool of Farlp, suggesting that pheromones may activate export of Farlp by Msn5p/ Ste21p or may inhibit its nuclear import. Moreover, no remaining nuclear staining of Farlp-nls1 was observed in cells overexpressing Msn5p/Ste21p (data not shown). In contrast, overexpression of Msn5p/Ste $21 \mathrm{p}$ did not alter nuclear localization of Rap1p- $\Delta 303-416-G F P$ (Fig. 3B), demonstrating that Msn5p/Ste21p is specific and does not perturb indiscriminately nuclear transport. Importantly, overexpression of Msn5p/Ste21p did not activate the pheromone response pathway as measured by the induction of the reporter FUS1-lacZ (Fig. 3D). Moreover, expression of Msn5p/Ste21p was able to trigger relocalization of Farlp in strains deleted for STE7 or STE20, demonstrating that activation of the mating 
A

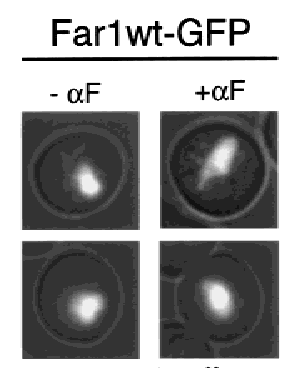

$\Delta$ ste21 cells

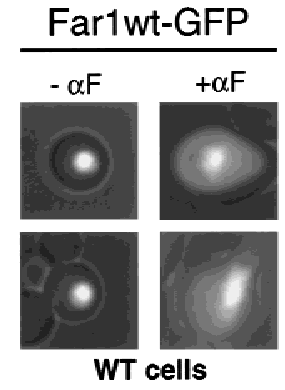

B

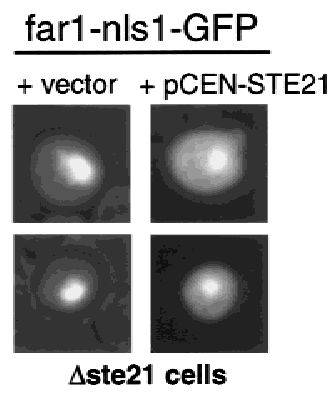

Figure 2. The exportin Msn5p/Ste21p is required to export Farlp. (A) Farlp-GFP was expressed in wildtype cells (right) or cells deleted for MSN5/STE21 (left) and treated (right row) or not treated (left row) with $\alpha$-factor for $6 \mathrm{hr}$. Photographs show GFP fluorescence superimposed with phase contrast. Note that Farlp-GFP remains nuclear in $\Delta m s n 5 /$ ste21 cells treated with $\alpha$-factor. $(B) \Delta m s n 5 /$ ste21 cells expressing Farlp-nls1-GFP were transformed with either an empty control plasmid (vector; left row) or a low copy number plasmid encoding MSN5/STE21 (pCENSTE21; right row). Cells were analyzed as above. Note that Farlp-nls1-GFP is predominantly nuclear in $\Delta m s n 5 / s t e 21$. pathway was not required to export Farlp under these conditions (Fig. 3C). Taken together, these results demonstrate that overexpression of Msn5p/Ste21p is sufficient to relocalize Farlp to the cytoplasm in a mating pheromone pathway-independent manner, and strongly suggest that Msn5p/Ste21p functions as an exportin for Farlp in vivo.

\section{Msn5p/Ste21p binds to Far1p}

in a manner dependent on Gsp1p-GTP

Because exportins have been shown to bind directly to their target proteins in a Ran-GTP-dependent manner, we tested whether Msn5p/Ste21p and Farlp are able to interact with each other by coimmunoprecipitation (Fig. 4) and two-hybrid assays (Table 1; Fig. 5). Myc-tagged Msn5p/Ste21p was immunoprecipitated with 9E10 antibodies from extracts prepared from wild-type cells (Fig. $4 \mathrm{~A}, \mathrm{~B}$, lanes $1-6,8,9$ ) or cells harboring a temperature-sensitive GSP1 allele (lanes 10-12), which express Farlp from the inducible $G A L$ promoter. The immunoprecipitates were then examined for the presence of Farlp by immunoblotting. Farlp readily coimmunoprecipitated with myc-tagged Msn5p/Ste21p (lanes 4,6), whereas no interaction was detected in cells expressing untagged Msn5p/Ste21p (lanes 2,8). Likewise, no interaction between Msn5p/Ste21p and Farlp could be detected when extracts were prepared from $g s p 1$ cells shifted to $35^{\circ} \mathrm{C}$ for $3 \mathrm{hr}$ (lanes 10,11), indicating that Gsplp is required for binding of Farlp to Msn5p/Ste21p. Expression of a GTPlocked mutant form of Gsplp (Gsplp-G21V) restored binding of Farlp and Msn5p/Ste21p in gsp1-1 cells (Fig. 4B, lane 12), although the strain was still unable to grow at the restrictive temperature (data not shown). To further corraborate these results, we performed in vitro binding assays (Fig. 4C): Gsplp-Myc expressed in Escherichia coli was immunoprecipitated, loaded with either GTP $\gamma \mathrm{S}$ or GDP, and incubated with yeast extracts containing Msn5p/Ste21p, Farlp, or both proteins as indicated. Interestingly, Farlp bound Gsplp-Myc only in the presence of Msn5p/Ste21p (cf. Lanes 14 and 18), suggesting that all three proteins together form a complex. Furthermore, Farlp interacted preferentially with GsplpMyc in its GTP-bound form (cf. lanes 17 and 18). Taken together, these results suggest that Farlp and Msn5p/
Ste21p interact with each other in a Gsp1p-GTP-dependent manner.
A

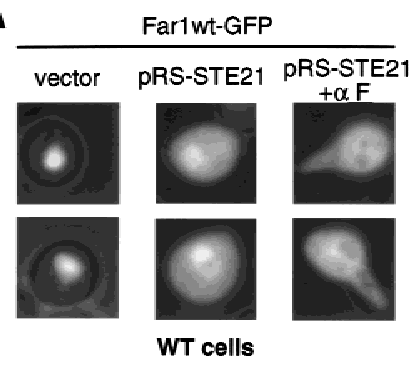

C

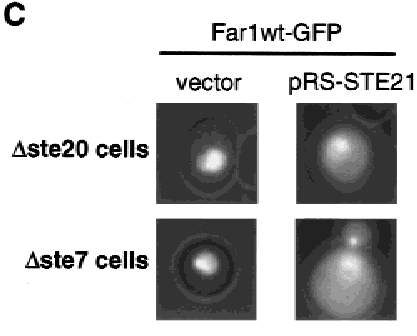

B
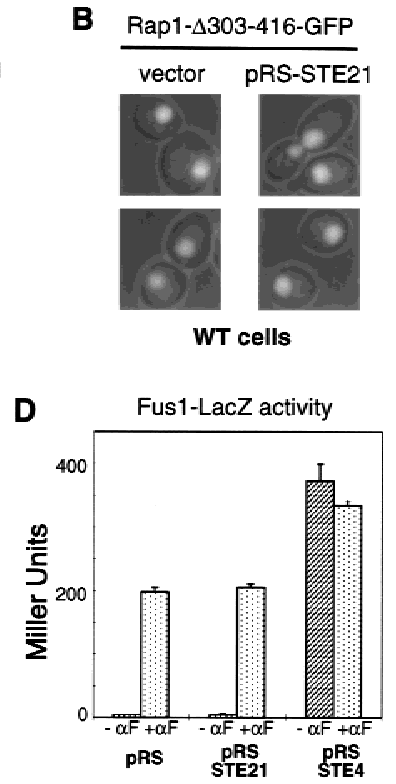

Figure 3. Overexpression of Msn5p/Ste21p is sufficient to export Farlp. $(A, B)$ Cells expressing Farlp-GFP $(A)$ or for control Raplp- $\Delta 303-416$-GFP $(B)$ were transformed with a control plasmid (vector; left rows) or a plasmid allowing overexpression of Msn5p/Ste21p from the inducible GAL promoter (pRS-STE21; right rows). Cells were grown in the presence of galactose and analyzed by fluorescence microscopy. Where indicated $\alpha$-factor was added for $3 \mathrm{hr}$. Note that complete cytoplasmic localization of Farlp requires overexpression of Msn5p/Ste21p and addition of $\alpha$-factor. (C) Redistribution of Farlp to the cytoplasm does not require an intact mating pathway. $\Delta$ ste20 (top) or $\Delta$ ste 7 cells (bottom) expressing Farlp-GFP were transformed with a control plasmid (vector; left row) or a plasmid allowing overexpression of Msn5p/Ste21p from the inducible GAL promoter (pRSSTE21; right row) and analyzed as described above. $(D)$ The ability of cells carrying a control plasmid (pRS) or plasmids allowing overexpression of Msn5p/Ste21p (pRS-STE21) or Ste4p (pRSSTE4) to induce the reporter FUS1-lacZ was determined either in the absence $(-\alpha \mathrm{F})$ or presence of $\alpha$-factor $(+\alpha \mathrm{F})$. Bars show mean $\beta$-galactosidase activity \pm S.D. for four independent transformants. Note that overexpression of Msn5p/Ste21p does not activate the pheromone response pathway. 
Blondel et al.

A

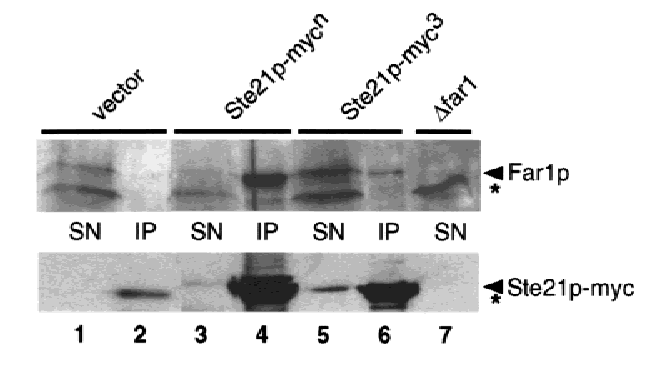

C

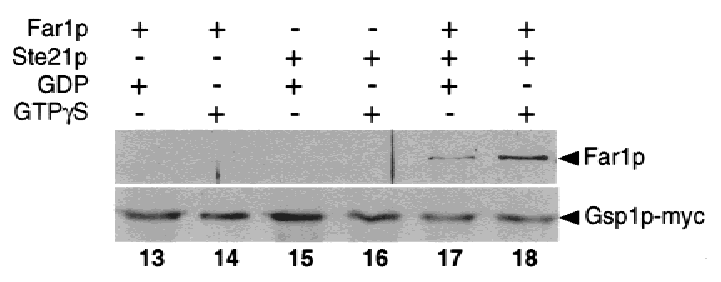

B
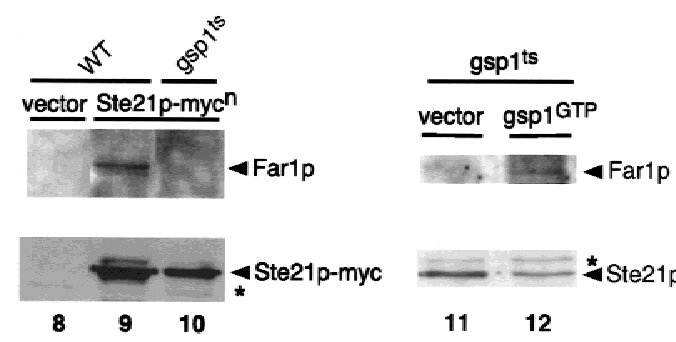

D

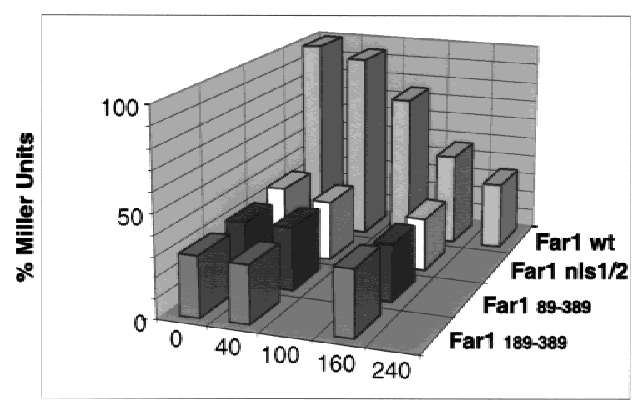

time after pheromone addition (minutes)

Figure 4. Farlp interacts with Msn5p/Ste21p in a Gsp1p-GTP-dependent manner. $(A, B)$ Msn5/Ste21p-myc was immunoprecipitated with $9 E 10$ antibodies from extracts prepared from wild-type $(\mathrm{K} 699$; lanes 1-6, 8,9) or temperature-sensitive gsp1 cells (YSH80; lanes 10-12) expressing Farlp and either untagged Msn5p/Ste21p (lanes 1,2,8), Msn5p/Ste21p-myc ${ }^{\mathrm{n}}$ (lanes 3,4,9-12) or Msn5p/Ste21p-myc ${ }^{3}$ (lanes 5,6). The immunoprecipitates (IP; lanes 2, 4, 6, 8-12) and an aliquot of the supernatant before immunoprecipitation (SN; lanes 1,3,5,7) were analyzed for the presence of Farlp (top) or Msn5p/Ste21p-myc (bottom) by immunoblotting. Expression of Gsp1-GTP (YBM100; gsp1-G21V, lane 12) restored the ability of Msn5p/Ste21p to interact with Farlp. Cells lacking Far1p (YMP1054, lane 7) were included to control for the specificity of the antibodies. The arrowhead marks the position of Farlp (top) or Msn5p/Ste21p-myc (bottom); the asterisk points to the position of proteins that cross-reacts with the antibodies. Note that Far1p and Msn5p/Ste21p interact in a Gsplp-dependent manner. $(C)$ Sepharose beads containing immunoprecipitated Gsplp-Myc expressed in E. coli and loaded with either GTP $\gamma$ S (lanes 14,16,18) or GDP (lanes 13,15,17) were incubated with yeast extracts containing as indicated Msn5p/Ste21p and Farlp expressed from the GAL promoter. Bound proteins were eluted and analyzed by immunoblotting for the presence of Farlp (top) and Gsplp-Myc (bottom). Note that Farlp preferentially bound Gsplp-GTP, but only in the presence of Msn5p/Ste21p. (D) Two-hybrid analysis of Msn5p/Ste21p and either wild-type (wt) or cytoplasmic Farlp mutant proteins in response to pheromones (times in minutes after addition of $\alpha$-factor). The interaction was quantified as described and shown as percentage of Miller units relative to wild-type controls without pheromones. Note that the interaction between Msn5p/Ste21p and wild-type Farlp but not cytoplasmic mutant forms of Farlp decreases in an $\alpha$-factor-dependent manner.

Farlp also interacted with Msn5p/Ste21p by two-hybrid assay (Table 1; Fig. 4D and 5). Deletion analysis of Farlp revealed that the domain of Farlp, which binds Msn5p/Ste21p, was located between amino acids 285 and 390 (Table 1). Interestingly, this domain overlaps with the binding site for $\mathrm{Cdc} 28 \mathrm{p}-\mathrm{Cln} 2 \mathrm{p}$ (Peter et al. 1993; Gartner et al. 1998), suggesting that Msn5p/Ste21p and Cdc28p-Cln2p kinase might compete for binding to Farlp. Although this segment of Farlp does not contain a classic leucine-rich hydrophobic (NES) sequence, we found a motif that is conserved in Farlp from Candida albicans and is also present in Ste5p, suggesting that Farlp may use a novel type of NES. Consistent with this notion, we observed that Ste5p-GFP was exported after overexpression of Msn5p/Ste21p, and conversely Ste5pGFP remained nuclear in $\Delta m s n 5 / \Delta s t e 21$ cells treated with $\alpha$-factor, suggesting that Ste5p is also a target of Msn5p/Ste21p (data not shown). To test whether this conserved motif is required to export Farlp in vivo we deleted the Msn5p/Ste21p-binding site on Farlp (Farlp$\Delta 285-390)$. As shown in Table 1, Farlp- $\Delta 285-390$ was unable to interact with Msn5p/Ste21p and importantly, both $\alpha$-factor treatment and overexpression of Msn5p/ Ste21p were unable to export Farlp- $\Delta 285-390$ from the nucleus (data not shown, see below). Thus, the ability of Farlp to bind to Msn5p/Ste21p correlates with the ability of Farlp to relocalize to the cytoplasm, suggesting that binding of Farlp to Msn5p/Ste21p is required to export Farlp in response to pheromones. However, this putative NES fused to GFP containing the NLS of Pho4p (Kaffmann et al. 1998a) was only able to induce nuclear export weakly even when Msn5p/Ste21p was overexpressed (data not shown), suggesting that this domain may not be sufficient to function as an export signal in vivo.

\section{Binding of Far1p and Msn5p/Ste21p} may not be regulated by pheromones

To test whether the interaction between Farlp and Msn5p/Ste21p is regulated by pheromones we performed coimmunoprecipitation and two-hybrid analysis in cells treated or not treated with $\alpha$-factor. As shown in Figure $4 \mathrm{D}$, the interaction between wild-type Farlp and Msn5p/ 


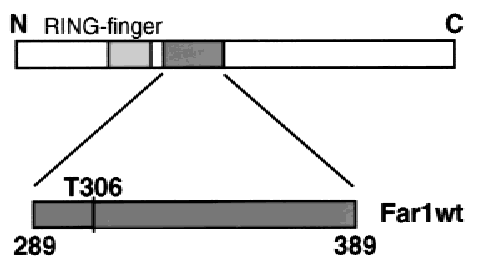

$\operatorname{far} 1 \Delta(304-308)$
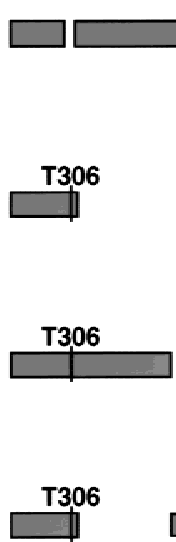

$\operatorname{far} 1 \Delta(312-338)$

\ $\operatorname{far} 1 \Delta(312-382)$
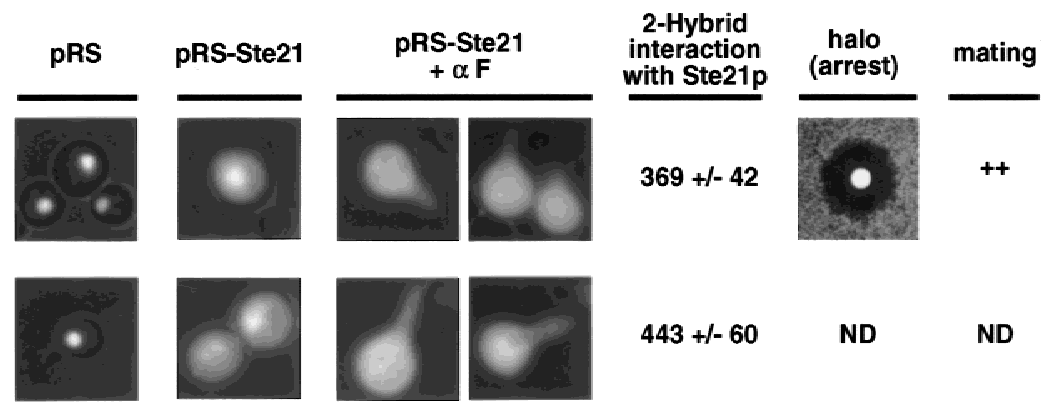

$443+1-60$

ND

ND
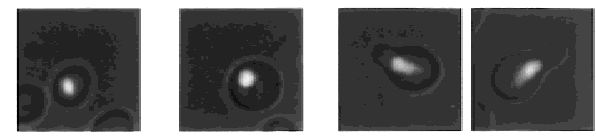

0
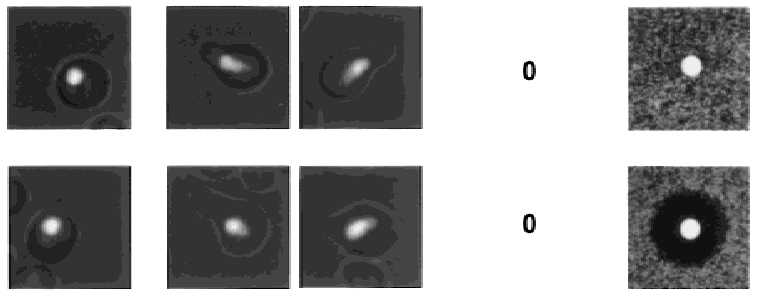

$+1-$
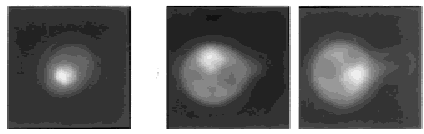

$107+/-23$

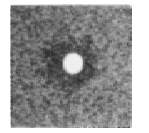

$+1-$

Figure 5. Binding of Farlp and Msn5p/Ste21p is required for efficient mating but not cell cycle arrest. Cells expressing wild-type Farlp-GFP (Farlwt; top row) or mutant Farlp-GFP lacking various parts of the Msn5p/Ste21p binding domain (bottom rows) were transformed with a control plasmid (pRS; left row) or a plasmid expressing Msn5p/Ste21p from the inducible GAL promoter (pRSSTE21; right rows). Where indicated cells were treated with $\alpha$-factor for $3 \mathrm{hr}$. Full-length or the various deletion mutants of Farlp are schematically represented on the left; deleted amino acids are indicated in parentheseis. The Farlp mutants were also tested for their ability to interact with Msn5p/Ste21p by two-hybrid assay; Miller units with standard deviations are shown. Cells deleted for FAR1 (YMP1054) transformed with low copy number plasmids expressing wild-type Farlp (top row) or the indicated Farlp mutant proteins (bottom rows) from the endogenous promoter were tested for their ability to arrest the cell cycle by halo assay, or for their ability to mate against the mating tester IH2625. (++) Wild-type mating; (+) -) strongly reduced mating; (-) sterile; (ND) not determined. Note that the Msn5p/Ste21p-binding domain of Farlp is required for nuclear export and efficient mating in vivo.

Ste21p decreased in a time-dependent manner in cells exposed to pheromones with kinetics that mirror the cytoplasmic accumulation of Farlp. We interpret this result to indicate that pheromones do not increase the interaction between Farlp and Msn5p/Ste21p, and that cytoplasmic accumulation of Farlp reduces the transcriptional readout of the two-hybrid assay that occurs in the nucleus. Consistent with this explanation, the interaction between Msn5p/Ste21p and several cytoplasmic Farlp mutants lacking their nuclear localization signal was decreased to levels comparable to wild-type Farlp in pheromone-treated cells, and importantly, no further decrease was observed after pheromone treatment (Fig. 4D). Likewise, Farlp and Msn5p/Ste21p were able to coimmunoprecipitate with similar efficiency in cells treated or not treated with $\alpha$-factor (data not shown), suggesting that phosphorylation of Farlp does not increase their interaction. In addition, although redistribution of Farlp in response to pheromones was dependent on Fus3p in vivo (M. Blondel and M. Peter, unpubl.), the interaction between Farlp and Msn5p/Ste21p as assayed by two-hybrid analysis was neither dependent on FUS3 (Table 1) nor on the sites on Farlp, which are phosphorylated by Fus3p in response to pheromones (Table 1; Gart- ner et al. 1998). Taken together, we conclude that the binding of Farlp and Msn5p/Ste21p may not be regulated by pheromones, although it remains possible that a weak effect could have been masked because the proteins were overexpressed. Therefore, nuclear export of Farlp may be constitutive or regulated by nuclear retention.

The requirements for binding of Far1p to Cdc28p-Clnp and the exportin Msn5p/Ste21p can be mutationally separated

Farlp- $\Delta 285-390$ remained in the nucleus in $\alpha$-factortreated cells (data not shown), but no longer interacts with Cdc28p-Clnp and therefore is unable to arrest the cell cycle in response to pheromones (Peter et al. 1993). To separate the cell cycle arrest and export functions we constructed several short deletion mutants within this domain (Fig. 5). Any Farlp deletion mutant that removed threonine 306 (T306) was unable to arrest the cell cycle as determined by halo assay (Fig. 5; data not shown), consistent with the result that phosphorylation of T306 by Fus $3 p$ regulates its binding to Cdc28p-Clnp (Peter et al. 1993; Gartner et al. 1998). In contrast, Farlp-4338- 
Blondel et al.

Table 1. Two-hybrid analysis of the interaction between Msn5p/Ste21p and Far1p

\begin{tabular}{|c|c|}
\hline Activation domain fusion & Miller units \pm S.D. \\
\hline $\begin{array}{l}\text { WT(EGY48) } \\
\text { Farlp }(1-830) \\
\text { Farlp }(353-830) \\
\text { Farlp }(1-389) \\
\text { Farlp }(174-285) \\
\text { Farlp }(89-389) \\
\text { Farlp }(189-389) \\
\text { Farlp }(289-389) \\
\text { Farlp } \Delta(285-390)\end{array}$ & $\begin{array}{c}415 \pm 117 \\
0 \\
877 \pm 194 \\
0 \\
327 \pm 110 \\
255 \pm 71 \\
253 \pm 88 \\
0\end{array}$ \\
\hline $\begin{array}{l}\text { far1s } \\
\quad \text { Far1p }(1-389) \\
\text { Far1p }(1-392) \text { A26 A87 A114 A324 V341 A346 } \\
\text { Far1p }(1-392) \text { A26 A87 A114 A306 V341 A } 346\end{array}$ & $\begin{aligned} 958 & \pm 73 \\
1044 & \pm 78 \\
951 & \pm 126\end{aligned}$ \\
\hline $\begin{array}{l}\text { far1s fus3 } 3 \\
\quad \text { Farlp }(1-830) \\
\text { Farlp }(1-389)\end{array}$ & $\begin{array}{l}492 \pm 18 \\
801 \pm 30\end{array}$ \\
\hline
\end{tabular}

Full-length or various mutants of Farlp fused to an activation domain $(\mathrm{AD})$ were tested for their ability to interact with fulllength Msn5p/Ste21p fused to a DNA-binding domain by twohybrid analysis. The numbers in parenthesis indicate the amino acids of Farlp fused to the AD, except in $\operatorname{Farlp} \Delta(285-390)$, where they indicate the deleted amino acids. The mutations in the Fus3p phosphorylation sites are indicated in small letters (Gartner et al. 1998). Expression of the $\beta$-Gal reporter was quantified as described and shown as Miller units with standard deviations. The interaction was tested in either a wild-type strain (EGY48), a strain deleted for FAR1 (YMP290), or a strain deleted for both FAR1 and FUS3 (YMP291). Note that a small domain within Farlp (amino acids 289-389) is necessary and sufficient to bind Msn5p/Ste21p.

382, which lacks the carboxy-terminal half of this domain, was able to arrest efficiently the cell cycle, but failed to interact with Msn5p/Ste21p by two-hybrid assay and as a consequence was unable to exit from the nucleus in vivo (Fig. 5). These experiments demonstrate that the requirements on Farlp for interacting with Cdc28p-Clnp or Msn5p/Ste21p are mutationally separable. Importantly, cells expressing Farlp- $-338-382$ exhibited a bilateral mating defect, demonstrating that nuclear export of Farlp is needed for efficient mating, most likely for oriented cell polarity.

\section{Msn5p/Ste21p is a nuclear protein that is not induced in response to $\alpha$-factor}

Because overexpression of Msn5p/Ste21p was sufficient to export Farlp from the nucleus, we tested whether pheromone may relocalize Farlp by increasing the levels of Msn5p/Ste21p. However, we found that the levels of Msn5p/Ste21p were not altered in response to pheromones (Fig. 6A), suggesting that post-translational modifications of either Far1p or Msn5p/Ste21p regulate export of Farlp in response to pheromones. To examine the subcellular localization of Msn5p/Ste21p, we epitope tagged Msn5p/Ste21p at its amino terminus with GFP and visualized the functional fusion protein by fluorescence microscopy. Consistent with Msn5p/Ste21p functioning as an exportin, the protein was found predominantly in the nucleus (Fig. 6B). We did not observe any differences in localization of Msn5p/Ste21p through the cell cycle or in cells exposed to $\alpha$-factor (bottom). Similar results were also obtained if Msn5p/Ste21p was localized by indirect immunofluorescence microscopy using myc-tagged Msn5p/Ste21p (data not shown).

\section{Msn5p/Ste21p plays multiple roles during yeast mating}

Next, we investigated the mating phenotype of cells deleted for STE21/MSN5. As observed previously (Akada et

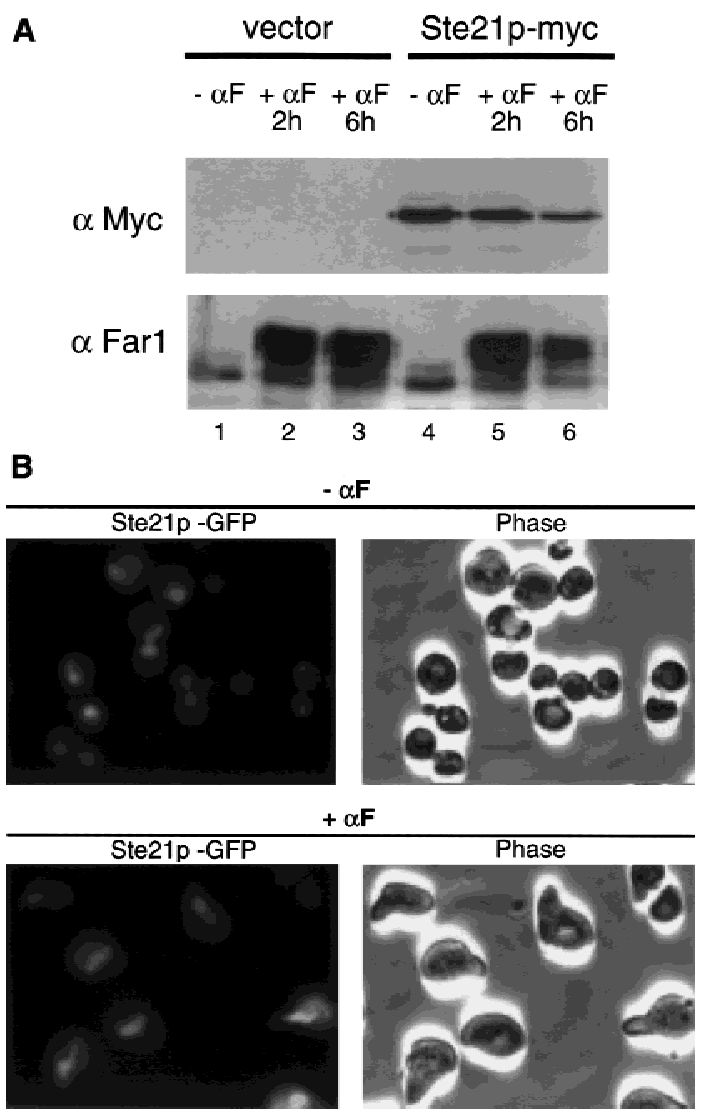

Figure 6. Msn5p/Ste21p is a nuclear protein that is not induced in response to pheromones. $(A)$ Cells expressing epitopetagged Msn5p/Ste21p (Ste21p-myc; lanes 4-6) or untagged Msn5p/Ste21p (vector; lanes 1-3) from the endogenous promoter were treated (lanes 2,3,5,6) or not treated with $\alpha$-factor for the times indicated (lanes 1,4). Extracts were immunoblotted with 9E10 antibodies (top) or antibodies specific for Farlp (bottom). Note that in contrast to Farlp the levels of Msn5p/Ste21p do not increase in $\alpha$-factor-treated cells. (B) Cells expressing Msn5p/Ste21p fused to GFP (Ste21p-GFP) from the endogenous promoter were treated (top) or not treated (bottom) with $\alpha$-factor and analyzed by fluorescence microscopy (left). The corresponding phase contrast pictures are shown on the right. Note that Msn5p/Ste21p is nuclear in $\alpha$-factor arrested cells and during all phases of the cell cycle. 
al. 1996), $\Delta$ ste21/msn5 cells mate with reduced efficiency (Fig. 7A, top); this mating defect is bilateral as the mating efficiency was decreased dramatically if both mating partners were deleted for STE21/MSN5 (Fig. 7A, bottom). Interestingly, $\Delta m s n 5 /$ ste21 cells were able to induce the transcripts of FUS1 and FAR1 efficiently in response to pheromones (Fig. $7 \mathrm{C}$ ), demonstrating that Msn5p/Ste21p is not required for signal transduction. Likewise, cells lacking Msn5p/Ste21p were able to arrest the cell cycle in response to pheromones in a FAR1-dependent manner (Fig. 7B), suggesting that cytoplasmic Farlp is not required for cell cycle arrest (see also below). However, $\Delta m s n 5 /$ ste21 cells displayed a reduced ability to form mating projections (shmoos), and even after several hours in pheromones $>80 \%$ of the cells remained unpolarized (Fig. 7D), suggesting that Msn5p/Ste21p is involved in exporting a protein involved in shmoo formation. This protein is unlikely to be Farlp, because Farlp is not needed to form shmoos (Valtz et al. 1995; M. Peter, unpubl.). Consistent with these observations, we found that overexpression of cytoplasmic Farlp was not sufficient to suppress the mating defect of $\Delta m s n 5 / s t e 21$ cells (data not shown). In addition, MSN5/STE21 and
FAR1 were synthetic sterile (data not shown), supporting an additional role of $\mathrm{Msn} 5 \mathrm{p} /$ Ste21p during mating. Thus, besides Far1p, Msn5p/Ste21p must export yet unknown targets involved in shmoo formation and perhaps other steps of mating.

\section{Nuclear and cytoplasmic Far1p play distinct roles during mating}

Next, we examined the functional importance of Farlp localization for its cell cycle arrest and mating function. Farlp is required for oriented cell polarization during mating (Dorer et al. 1995; Valtz et al. 1995) and is thought to function as a cytoplasmic adaptor that recruits polarity establishment proteins to the site of extracellular signaling marked by the heterotrimeric $\mathrm{G}$ pro-

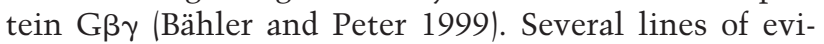
dence suggest that cytoplasmic Farlp is required for this polarization function. First, like $\Delta m s n 5 / s t e 21$ cells, $\Delta$ far1 cells expressing Farlp- $\Delta 338-382$ mutant protein, which can no longer be exported in response to pheromones, exhibited a mating defect (see Fig. 5). Second, wild-type cells expressing cytoplasmic Farlp-nls1 or
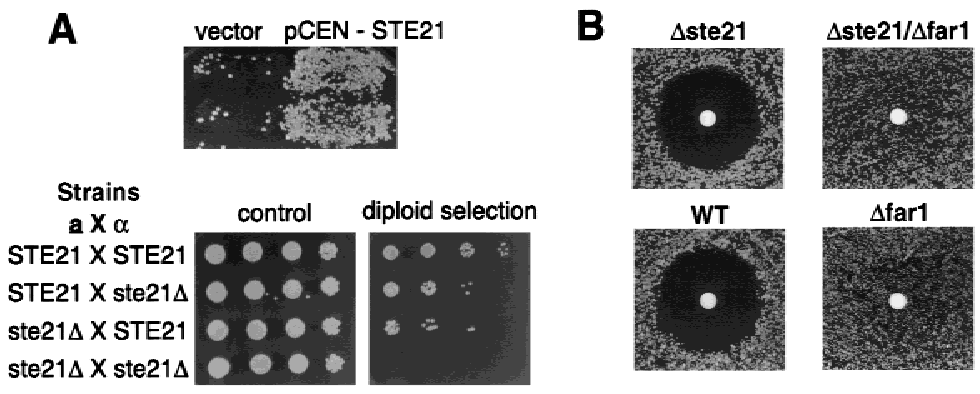

\section{C}
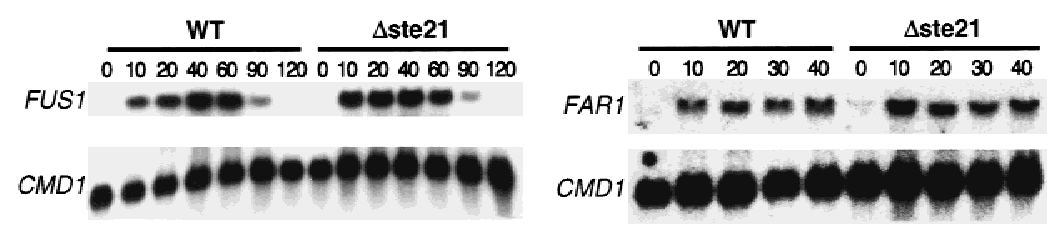

D

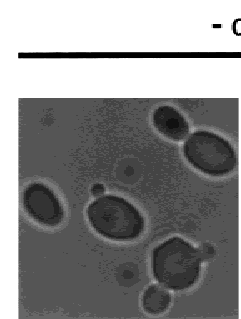

$-\alpha \mathbf{F}$

$+\alpha \mathbf{F}$
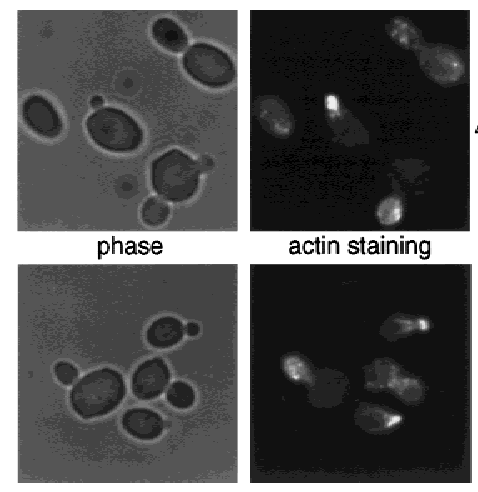

$\Delta$ ste21
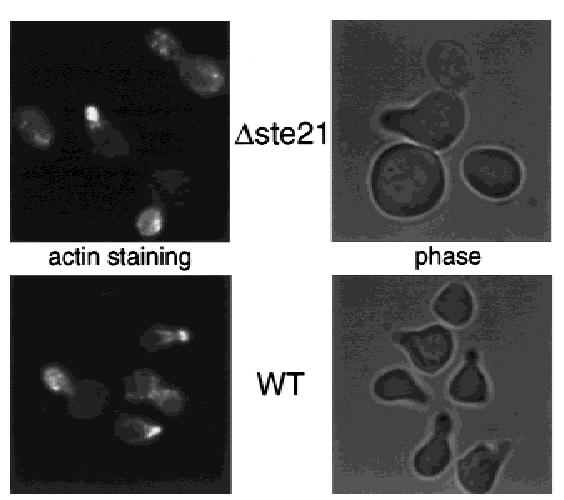

phase

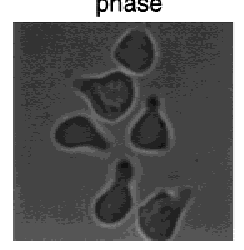

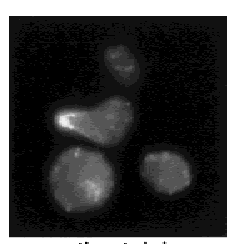

actin staining

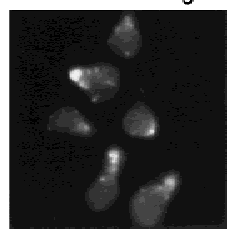

Figure 7. Cells lacking Msn5p/Ste21p exhibit a bilateral mating defect but are able to arrest their cell cycle. $(A$; top $)$ Mating assay with the mating tester IH2625 and $\Delta m s n 5 /$ ste21 cells (PAY20) transformed with a control plasmid (vector) or a plasmid carrying MSN5/STE21 (pCEN-STE21). (Bottom) Mating assays with either MATa or $M A T \alpha$ wild-type or $\Delta m s n 5 / s t e 21$ cells as indicated. Serial dilutions of the mating reactions were spotted on control plates (left) or selective plates where only diploid cells are able to grow (right). Note that $\Delta m s n 5 /$ ste21 cells exhibit a bilateral mating defect. $(B)$ The indicated strains were analyzed by halo assay for their ability to arrest the cell cycle in response to $\alpha$-factor. Note that cells lacking Msn5p/Ste21p efficiently arrest their cell cycle in a manner dependent on Farlp. The following strains were analyzed: $\Delta$ ste21 (PAY20); $\Delta$ ste21 $\Delta$ far1 (YMP1067); wt (K699) and $\Delta$ far1 (YMP1054). (C) $\Delta m s n 5 / s t e 21$ cells (PAY20) were able to efficiently induce mating-specific transcription of FAR1 (right) and FUS1 (left). Northern analysis of total RNA isolated from wild-type (K699; left lanes) or $\Delta m s n 5 /$ ste21 cells (PAY20, right lanes) treated with $\alpha$-factor for the times indicated (in minutes). A probe against $C M D 1$ RNA was used as total RNA loading control (bottom). (D) The morphology of cells deleted for Msn5p/Ste21p (PAY20; top row) or wild-type cells (K699; bottom row) in the absence (left rows) or presence of $\alpha$-factor (right rows) was analyzed by phase contrast microscopy (left). Actin distribution is directed toward the growing bud or shmoo tip as visualized after staining with rhodamine-phalloidin (right). 
Blondel et al.

cells overexpressing Msn5p/Ste21p mated with comparable or slightly increased efficiency (Fig. 8E, right column), suggesting that additional Farlp in the cytoplasm may improve the mating function of Farlp. Finally, $\sim 60 \%$ of haploid cells overexpressing cytoplasmic Farlpnls1, but not wild-type Farlp, budded in a bipolar or random instead of axial pattern (Table 2; Chant 1996), suggesting that compartmentalization in the nucleus prevents Farlp from interfering with polarity establishment proteins in the absence of pheromones. Taken together, these results indicate that the polarization function of Farlp during mating requires cytoplasmic Far1p.

In contrast, nuclear Farlp appears to be required for cell cycle arrest in response to pheromones. We have shown above that $\Delta$ ste21/msn5 cells failed to export Farlp but were able to arrest efficiently their cell cycle in
Table 2. Overexpression of cytoplasmic Far1p interferes with the budding pattern

\begin{tabular}{llccc}
\hline & \multicolumn{3}{c}{ Budding pattern $(\%)$} & No. of cells \\
\cline { 2 - 4 } Plasmid & 76 & 23.5 & 0.5 & 200 \\
axial & bipolar & random & counted \\
\hline pRD53 & 72 & 26.5 & 1.5 & 400 \\
pRD53-Far1wt & 34.5 & 54 & 11.5 & 400 \\
pRD53-far1-n1s1 & 42 & 44 & 14 & 200 \\
\hline pRD53-far1-n1s1,2 & 42 & &
\end{tabular}

Cells deleted for FAR1 (YACB169) were tranformed with an empty control plasmid (pRD53) or plasmids allowing overexpression of wild-type Farlp, Farlp-nls1 or Farlp-nls1/2 from the inducible $G A L$ promoter. Cells were grown in galactose at $30^{\circ} \mathrm{C}$, the budding pattern was determined as described and presented as percent of total cells. Only cells with three or more bud scars were included in the analysis.
A
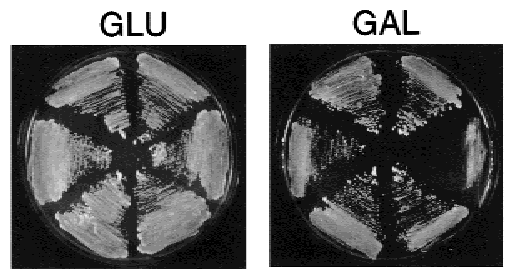

กับ
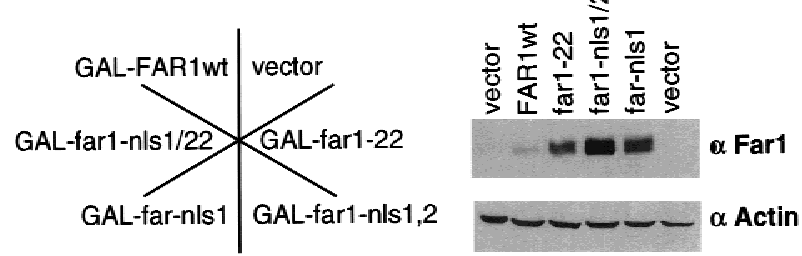

B

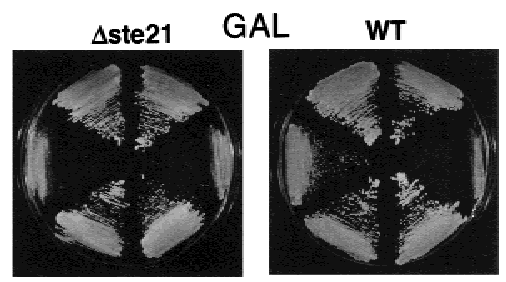

C

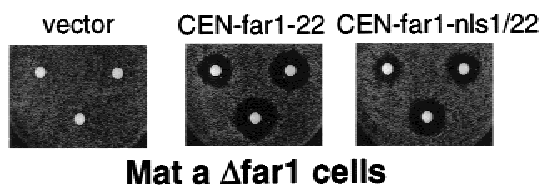

D

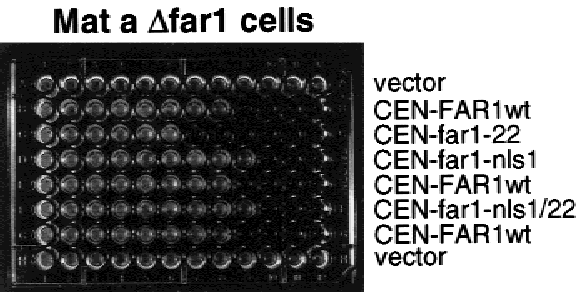

$\mathbf{E}$

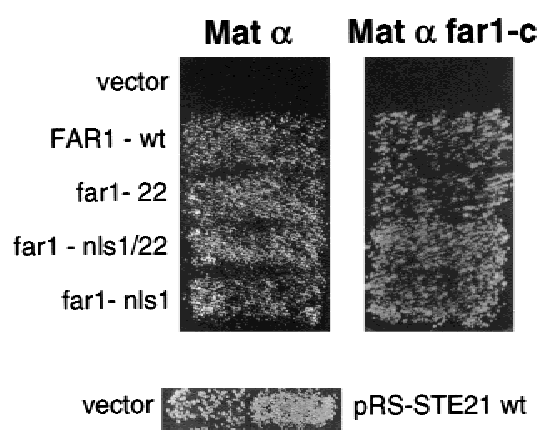

Figure 8. Nuclear Farlp is required to arrest the cell cycle in response to pheromones, whereas cytoplasmic Farlp is necessary for efficient mating. (A) Wild-type cells (K699) were transformed with plasmids allowing overexpression of wild type or various mutant Farlp from the inducible GAL promoter as indicated, and grown on plates containing glucose (GLU; Farlp not expressed) or galactose (GAL; Farlp expressed). Extracts were prepared from cells and immunoblotted with specific antibodies against Farlp (top) or actin (bottom). Note that Farlp-22 is only toxic in the presence of a functional NLS. (B) Wild-type strains (K699, right) or strains deleted for MSN5/STE21 (Aste21; left) were transformed with the plasmids as indicated above and grown on media containing galactose. Note that in contrast to wild-type cells Far1-nls1/22 is toxic in $\Delta m s n 5 / s t e 21$ cells. (C) Cell deleted for FAR1 but harboring an empty plasmid (vector, left) or low copy number plasmids expressing Farlp-22 (middle) or Farlp-nls1/22 (right) from the endogenous promoter were analyzed by halo assay for their ability to arrest the cell cycle in response to pheromones. The circles contained 2,10 , and $20 \mu \mathrm{g}$ of $\alpha$-factor. $(D)$ The minimal concentration of $\alpha$-factor required to arrest cells expressing wild type or the indicated mutant Farlp from the endogenous promoter was determined by serial dilutions as described. Note that efficient cell cycle arrest in response to pheromones requires Farlp with a functional NLS. (E) Cells deleted for FAR1 but harboring an empty plasmid (vector) or low copy number plasmids expressing wild type or the indicated Farlp mutants from the endogenous promoter were analyzed for their ability to mate with wild-type (IH1793; left) or mating-reduced FAR1-C mating testers (IH2625, right). Note that cytoplasmic Farlp does not reduce the mating efficiency. Wild-type cells (K699) harboring an empty plasmid (vector; left patch) or a plasmid allowing overexpression of Msn5p/Ste21p (pRS-STE21; right patch) were mated to wild-type mating testers (IH1793). Note that overexpression of Msn5p/Ste21p slightly increases the mating efficiency. 
response to pheromones, suggesting that nuclear Farlp is sufficient for cell cycle arrest. Likewise, Farlp- $\Delta 338-382$ can no longer be exported in response to pheromones but is able to fully complement the cell cycle arrest defect of $\Delta$ far1 cells. Previously, we have found that overexpression of a nuclear, stable mutant form of Farlp (Farlp-22) arrests cells in the $G_{1}$ phase of the cell cycle by inhibiting the Cdc28p-Clnp kinase (Henchoz et al. 1997). In contrast, cells overexpressing a cytoplasmic double mutant between Farlp-22 and NLS1 (Farlp-nls1/22) were viable and able to divide, although the Farlp-nls1/22 protein was expressed at similar or even higher levels than Farlp-22 (Fig. 8A). Interestingly, cytoplasmic Farlp was stable and no longer subjected to ubiquitin-mediated degradation (M. Blondel and M. Peter, unpubl.), explaining the increased steady-state levels of Farlp-nls1 and Farlp-nls1/22. However, overexpression of Farlp-nls1/ 22 is toxic in cells deleted for MSN5/STE21 (Fig. 8B), which accumulated Farlp-nls1/22 in the nucleus (data not shown) because of a defect in the export system, demonstrating that Far1p-nls1/22 is functional and able to arrest the cell cycle when localized in the nucleus. Consistent with these findings, $\Delta$ far 1 cells expressing Farlp-nls1/22 from the endogeneous promoter exhibited an eightfold reduced ability to arrest the cell cycle in response to pheromones compared to $\Delta$ far 1 cells expressing Farlp-22 (Fig. 8C,D). Taken together, we conclude that nuclear Farlp is required to arrest the cell cycle in response to pheromones.

\section{Discussion}

The subcellular localization of Farlp is controlled by activation of the pheromone response pathway during mating; in the absence of pheromones, Farlp is predominantly nuclear, whereas in the presence of pheromones Farlp accumulates in the cytoplasm. We show here that the localization of Farlp is under the control of both nuclear import and export pathways and have identified Msn5p/Ste21p as a specific exportin for Far1p. Export of Farlp in response to pheromones requires Msn5p/ Ste21p, which interacts with Farlp in a manner dependent on Gsplp-GTP. Our results further suggest that nuclear Farlp is required for its cell cycle arrest function, whereas cytoplasmic Farlp interacts with G $\beta \gamma$ and the polarity establishment proteins to orient cell polarity during mating.

\section{The subcellular localization of Far1p is mediated by nuclear import and export}

In the absence of pheromones Farlp is localized predominantly in the nucleus (Henchoz et al. 1997). As shown here nuclear localization depends on at least one bipartite NLS, which is located in the amino-terminal domain of Farlp. Farlp lacking this region or harboring point mutations in the basic residues within the bipartite NLS accumulates predominantly in the cytoplasm. NLSs are recognized by import receptors that target specific proteins to the nucleus. For example, Kap123p was shown to be involved in the import of the ribosomal protein L25 (Rout et al. 1997; Schlenstedt et al. 1997), and Pselp is required to import Pho4p in response to phosphate starvation (Kaffmann et al. 1998a). At present, we do not know which import receptor is required for nuclear localization of Farlp.

In contrast, several lines of evidence strongly suggest that Msn5p/Ste21p functions as an exportin for Far1p, although we cannot rigorously exclude the possibility that Msn5p/Ste21p may indirectly inhibit nuclear import of Farlp. First, cytoplasmic accumulation of Farlp in response to pheromones was abolished in cells deleted for Msn5p/Ste21p. Second, Far1p accumulated in the cytoplasm of cells overexpressing Msn5p/Ste21p even in the absence of pheromones, and third, a cytoplasmic mutant of Farlp that harbors mutations in the major NLS becomes predominantly nuclear when expressed in $\Delta m s n 5 /$ ste21 cells. Fourth, Msn5p/Ste21p is localized in the nucleus, consistent with its proposed function as an exportin for Farlp. Fifth, Farlp coimmunoprecipitated with Msn5p/Ste21p in a manner dependent on GTPbound Gsp1p and also interacted with Msn5p/Ste21p by two-hybrid analysis. Finally, a small segment of Farlp, which is necessary and sufficient to interact with Msn5p/Ste21p, is required to export Farlp in vivo in response to pheromones. Signals have been defined that target proteins from the nucleus to the cytoplasm (Nakielny and Dreyfuss 1997; Weis 1998). The NES contained in the HIV Rev protein and PKI, an inhibitor of cAMP-dependent protein kinase $\mathrm{A}$, is a small sequence rich in leucine residues, which is bound by the export receptor Crm1p/Xpolp and Ran-GTP in the nucleus. The interaction domain between Farlp and Msn5p/ Ste21p does not contain an obvious leucine-rich NES, suggesting that Farlp uses a novel type of NES. However, the Msn5p/Ste21p-binding domain of Farlp was not able to export efficiently a nuclear GFP fusion protein, suggesting that this motif may not be sufficient to mediate Msn5p/Ste21p-dependent export in vivo. Nevertheless, together with the recently identified Msn5p/Ste21p targets Msn2p, Msn4p, and Pho4p it may be possible to deduce a consensus sequence, which may facilitate the identification of additional proteins exported by Msn5p/ Ste21p.

\section{Regulation of the subcellular localization of Far1p by pheromones}

The subcellular localization of Farlp is surprisingly dynamic and is regulated by both nuclear import and export. In the absence of $\alpha$-factor, Farlp is predominantly nuclear and import appears to overcome export. Addition of pheromones shifts the equilibrium and Farlp accumulates in the cytoplasm. It is not understood how pheromones alter this balance, but available results suggest a role for the MAPK Fus3p (M. Blondel and M. Peter, unpubl.). It is possible that Fus3p inhibits nuclear import, increases nuclear export, or both. Fus3p may also regulate the activity of nuclear or cytoplasmic docking sites that may retain Farlp in the nucleus in the absence 
of pheromones, or in the cytoplasm in the presence of pheromones (Hood and Silver 1999; Kaffmann and O'Shea 1999).

Nuclear import is regulated in many cases by phosphorylation of sites within or close to the NLS (Moll et al. 1991; Kaffmann et al. 1998a). Two consensus phosphorylation sites for Cdc28p kinase or MAPK are present within the major NLS of Farlp and it has been shown that this region of Farlp is heavily phosphorylated by Cdc28p kinases in vivo and in vitro (McKinney and Cross 1995). Thus, phosphorylation of these sites by Fus3p may prevent nuclear import of Farlp in response to pheromones. Alternatively, because Fus3p is required to inhibit Cdc28p-Clnp activity in response to pheromones (Elion et al. 1990; Peter et al. 1993), it is possible that phosphorylation of Farlp by Cdc28p-Clnp may be required for nuclear import. However, we found that Farlp is localized in the nucleus of $G_{1}$ cells arrested by depletion of the $G_{1}$ cyclins, suggesting that nuclear import was not dependent on Cdc28p kinase activity (data not shown). In addition, nuclear localization of Farlp is independent of the cell cycle position (Henchoz et al. 1997) and did not require Fus3p or any other component of the mating pathway (data not shown). Finally, a fusion protein between the 50 amino-terminal amino acids of Farlp (containing the NLS and the putative phosphorylation sites) with GFP was localized efficiently in the nucleus of cells treated (data not shown) or not treated with $\alpha$-factor (Fig. 1C); however, because we do not know whether this amino-terminal fragment of Farlp is phosphorylated efficiently in vivo, we cannot exclude the possibility that phosphorylation of these sites may inhibit nuclear import of full-length Farlp in response to pheromones.

It is clear that nuclear export of Farlp must occur even in the absence of pheromones, because Farlp-nls1 is nuclear in cells lacking Msn5p/Ste21p, whereas it is predominantly cytoplasmic in wild-type cells. Thus, a decrease in the rate of nuclear import can be compensated by decreasing the rate of nuclear export. Overexpression of Msn5p/Ste21p was sufficient to export Far1p in the absence of pheromones or a functional pheromone response pathway, suggesting that increased levels of Msn5p/Ste21p are able to shift the equilibrium. However, endogenous Msn5p/Ste21p levels were not altered in response to pheromones, indicating that post-translational mechanisms may regulate nuclear export of Farlp. Because Msn5p/Ste21p is required to export multiple proteins, not only during mating, but also in response to environmental conditions such as high phosphate levels, we favor a model where regulation of nuclear export occurs at the level of the substrate rather than at the level of the exportin or the export machinery. In support of this notion, recently it has been shown that Msn5p/ Ste21p specifically interacts with phosphorylated Pho4p and that phosphorylation of Pho4p is required for its nuclear export in vivo (Kaffmann et al. 1998b). However, although Farlp is a substrate of Fus3p (Peter et al. 1993; Tyers and Futcher 1993; Kranz et al. 1994; Gartner et al. 1998), the interaction between Farlp and Msn5p/Ste21p as assayed by two-hybrid analysis was not increased in response to pheromones and was neither dependent on the presence of Fus3p nor on the pheromone-dependent phosphorylation of Farlp (Table 1). Thus, these results suggest that Fus3p may not regulate directly binding of Far1p with its exportin Msn5p/Ste21p. Further work is required to elucidate the mechanism of regulation of cytoplasmic accumulation of Farlp by pheromones.

\section{Multiple roles of Msn5p/Ste21p during mating and response to various extracellular signals}

Several proteins have now been shown to be targets of the exportin Msn5p/Ste21p: the transcription factor Pho4p is exported by Msn5p/Ste21p under high phosphate conditions (Kaffmann et al. 1998b), and Msn5p/ Ste21p keeps Msn2p and Msn4p in the cytoplasm in the absence of stress conditions (Gorner et al. 1998; Alepuz et al. 1999). As shown here Msn5p/Ste21p exports Far1p in response to pheromones and cells lacking Msn5p/ Ste21p exhibit a bilateral mating defect. The signal transduction and cell cycle arrest functions of $\Delta \mathrm{msn} 5 /$ ste21 cells in response to pheromones are intact, but the cells exhibit a defect in projection formation and in orienting growth toward the mating partner. The latter defect is thought to result from a failure to export Farlp, which is necessary to target the polarity establishment proteins Bem1p, Cdc24p, and Cdc42p to the site of the incoming pheromone signal marked by G $\beta \gamma$ (Butty et al. 1998; Nern and Arkowitz 1999). However, cells lacking Farlp are able to form mating projections and thus Farlp cannot be the only Msn5p/Ste21p target that needs to be exported during mating, an observation that is supported by the synthetic sterility of cells lacking both Msn5p/ Ste21p and Farlp. In addition, we found that overexpression of cytoplasmic Farlp was not sufficient to bypass the need for Msn5p/Ste21p during mating, although cytoplasmic Farlp increased the mating efficiency of wildtype cells. Interestingly expression of a membranebound version of Ste5p (Ste5p-CTM; Pryciak and Huntress 1998) partially restored shmoo formation in $\Delta m s n 5 /$ ste21 cells (data not shown), suggesting that export of Ste5p may be necessary to form mating projections efficiently.

\section{The function of Far1p is required in two subcellular compartments}

Farlp is known to play two separable roles during yeast mating (Valtz et al. 1995): Farlp is required to arrest the cell cycle presumably through the inhibition of the Cdc28p-Clnp kinase (Peter and Herskowitz 1994; Gartner et al. 1998) and Farlp is necessary for oriented cell polarity by linking the polarity establishment proteins to Gß $\gamma$ (Butty et al. 1998; Nern and Arkowitz 1999). Several lines of evidence suggest that the cell cycle arrest function of Farlp requires nuclear localization of Farlp. First, cells expressing Farlp-nls1 with reduced ability to enter into the nucleus exhibit a modest cell cycle arrest defect 
in response to pheromones. Second, a dominant Farlp, which when overexpressed arrests the cell cycle by inhibiting the Cdc28p-Clnp kinase (Henchoz et al. 1997), is no longer toxic if the dominant mutation is combined with a mutation that inactivates the NLS. Finally, cells unable to export Farlp either because they lack the exportin Msn5p/Ste21p or because they express a mutant Farlp deleted for its NES (Farlp-\$338-382), are able to arrest efficiently the cell cycle in response to pheromones. In contrast, $\Delta$ far 1 cells expressing Farlp- $\Delta 338$ 382 exhibit a mating defect, although these cells are able to arrest and form normal mating projections. Similarly, $\Delta m s n 5 / s t e 21$ cells mate with reduced efficiency; we presume that this mating defect is partly due to the requirement of cytoplasmic Farlp to interact with Ste4p to perform its function as an adaptor for polarity establishment (Butty et al. 1998; Nern and Arkowitz 1999). Consistent with that notion, we found that cytoplasmic Farlp was sufficient for the mating function and even slightly increased the mating efficiency. In addition, overexpression of cytoplasmic Farlp interferes with the budding pattern of wild-type cells (Table 2), presumably through its interaction with polarity establishment proteins. It has been found previously that overexpression of a truncated Farl protein lacking 50 amino acids of the amino terminus interfered with bud formation after release from $\alpha$-factor arrest (McKinney and Cross 1995). Our results now show that this truncated Farlp protein lacks its major NLS and therefore, may interfere with the polarity establishment machinery during bud formation. Thus, these results suggest that sequestration in the nucleus might prevent Farlp from interacting with polarity establishment proteins in the absence of the physiological stimulus.

On the basis of these results we propose a model for how the cell cycle arrest and polarity establishment functions of Farlp may be coordinated (Fig. 9). In the absence of pheromones, low levels of Farlp are present because the expression of FAR1 is controlled at the transcriptional level by the pheromone pathway (Chang and Herskowitz 1990; Oehlen et al. 1996). Expressed Farlp is sequestered in an inactive form in the nucleus, where it is unable to interfere with the function of cytoplasmic polarity establishment proteins. Activation of the pheromone response pathway increases expression of Farlp. In addition, Farlp is phosphorylated by Fus3p, which enables Farlp to bind to the Cdc28p-Clnp kinase in the cell nucleus leading to cell cycle arrest (Peter et al. 1993; Gartner et al. 1998). Pheromones also trigger export of Farlp into the cytoplasm by a mechanism that requires the exportin Msn5p/Ste21p. Cytoplasmic Farlp interacts with Bem $1 p, C d c 24 p$, and Cdc $42 p$ and targets them to the activated heterotrimeric $\mathrm{G}$ protein to organize the actin cytoskeleton toward the incoming signal (Arkowitz 1999; Bähler and Peter 1999). Because Cdc28p-Clnp and Msn5p/Ste21p have at least partially overlapping binding sites it is possible that Msn5p/Ste21p and Cdc28p-Clnp compete for binding to Farlp. Such a mechanism may be important to coordinate the cell cycle arrest and polarity functions of Far1p (Fig. 9).

\section{Materials and methods}

Yeast strains, genetic manipulations, and database searches

Yeast strains are described in Table 3 . The genotypes of the yeast strains are W303, ade2-1, trp1-1, can1-100, leu2-3,112, his3-11,15, ura3, GAL $L^{+}, p s i^{+}$, ssd1-d2; A364a, trp1-289, leu23,112, his3-11,15, ura3-52, GAL'; and EG123: $\operatorname{trp} 1-\Delta 99$, leu2$\Delta 1$, ura3-52, ade2-101, unless noted otherwise. Standard yeast growth conditions and genetic manipulations were used as described (Guthrie and Fink 1991). Yeast transformations were performed by lithium acetate procedure (Ito et al. 1983). Strains deleted for FAR1 marked with LEU2 or URA3 were constructed using plasmids pMT870 digested with PVuII, or pFC13 digested with NotI. Strains deleted for MSN5/STE21 were constructed using plasmids pLH64 digested with NotI and XhoI, and strains deleted for STE7 were constructed using the plasmid pSL2270 digested with PstI and XhoI (Pinten and Sprague 1994). STE2O was deleted using the $\mathrm{kan}^{\mathrm{R}}$ cassette as described in Longtine et al. (1998). Strain YBM100 was constructed by integration of $G A L-g s p 1(G 21 V)$ at the URA3 locus of YSH80 by digesting the plasmid pSH125-1 with StuI. Transformants were selected on SD-URA plates at $25^{\circ} \mathrm{C}$ and tested for their inability to grow on

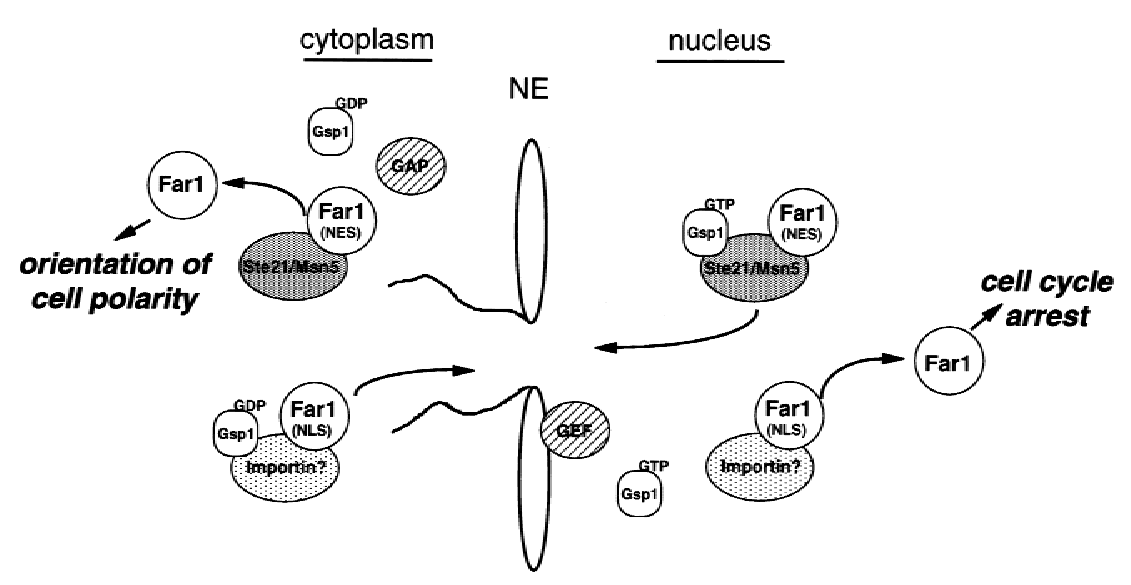

Figure 9. A schematic representation of the Farlp functions. In the absence of pheromones Farlp is exclusively nuclear because of the presence of functional NLS sequences. Nuclear Farlp is inactive as a cyclin-dependent kinase inhibitor (CKI) because it needs to be phosphorylated by the MAPK Fus3p to be able to bind to the Cdc28p-Clnp kinase (Peter et al. 1993; Gartner et al. 1998). Nuclear Farlp interacts with Msn5p/Ste21p in a Gsplp-dependent manner, which then transports Farlp into the cytoplasm. In the presence of pheromones the balance between import and export is shifted toward export presumably because of activation of Fus3p. Nuclear Farlp is required for cell cycle arrest, whereas cytoplasmic Farlp is needed for the establishment of oriented cell polarity. 
Table 3. Strains list

\begin{tabular}{|c|c|c|c|}
\hline $\begin{array}{l}\text { Strain } \\
\text { name }\end{array}$ & Relevant genotype & Background & Source \\
\hline K699 & MATa & W303 & Kim Nasmyth (IMP, Vienna, Austria) \\
\hline YMP1054 & MATa far1::LEU2 & W303 & Henchoz et al. (1997) \\
\hline PAY20 & MATa ste21::HIS3 & W303 & this study \\
\hline YMP1067 & MATa ste21::HIS3 far1::LEU2 & W303 & this study \\
\hline MJ 234 & MATa fus1::1acZ::URA3 & A364a & this study \\
\hline GA682 & 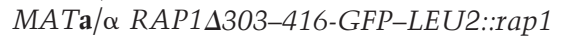 & SK1 & Monika Tsai (ISREC) \\
\hline YFD162 & MATa ste7::ADE2 bar1-1 far1s & W303 & Frank van Drogen (ISREC) \\
\hline YFD163 & MATa ste20::kan ${ }^{\mathrm{R}}$ bar1-1 far1s & W303 & Frank van Drogen \\
\hline YSH80 & MATa gsp1::hisG his3-1,15::gsp1ts(HIS3) & W303 & Shai Shaham \\
\hline IH1793 & $M A T \alpha \operatorname{lys} 1$ & & collection \\
\hline IH 2625 & MAT $\alpha$ far1c lys1 & & collection \\
\hline YACB169 & MATa far1::LEU2 & EG123 & this study \\
\hline LH90 & MATa ste21::TRP1 & $\mathrm{JC}-2 \mathrm{~B}$ & this study \\
\hline YMP290 & MATa far1 $\Delta$ bar1-1 & W303 & Gustav Ammerer \\
\hline YMP291 & $M A T \mathbf{a}$ far1 $\Delta$ fus3 $\Delta$ bar1-1 & W303 & this study \\
\hline \multirow[t]{2}{*}{ YBM100 } & MATa gsp1::hisG his3-1,15::gsp1ts(HIS3) & W303 & this study \\
\hline & GAL-gsp1(G21V)-URA3::ura3 & & \\
\hline
\end{tabular}

medium containing galactose and thermosensitivity at $37^{\circ} \mathrm{C}$. Database searches were performed using the SGD (Stanford University) and the NCBI BLAST programs (National Institutes of Health).

\section{Pheromone response and mating assays}

Pheromone response and mating assays were carried out as described (Valtz and Peter 1997). Mating assays were performed with both wild-type (IH1793) and orientation-defective far1-c mating testers (IH2625). Quantitative cell cycle arrest assays were performed in microtiter plates as described (Grishin et al. 1998). Each series uses twofold dilutions from well to well starting with $100 \mu \mathrm{g} / \mathrm{ml} \alpha$-factor; the last well contains no $\alpha$-factor. To analyze the expression of Msn5p/Ste21p in response to pheromones, cells (LH90) harboring a plasmid-allowing expression of Msn5p/Ste21p from the endogenous promoter (pLH287) were grown in selective media to early log phase, at which time $\alpha$-factor was added to $25 \mu \mathrm{g} / \mathrm{ml}$ final concentration (time 0 ). Aliquots were removed after the times indicated and the expression of Msn5p/Ste21p and Farlp was analyzed by immunoblotting as described. Induction of FAR1 or FUS1 mRNA in $\triangle m s n 5 /$ ste21 (PAY20) or wild-type cells (K699) was determined by Northern analysis as described previously (Martinez-Pastor et al. 1996).

\section{DNA manipulations}

Plasmids are described in Table 4. Standard procedures were used for recombinant DNA manipulations (Sambrook et al. 1989; Ausubel et al. 1991). PCR reactions were performed with the Expand polymerase kit as recommended by the manufacturer (Boehringer Mannheim). Oligonucleotides were synthesized by Genset (France) and the sequences are available upon request. Mutations were introduced by PCR and the correct sequence confirmed by sequencing. Internal deletion mutants of FAR1 were constructed by PCR by introducing in frame BgIII restriction sites. The XhoI-SphI fragment of FAR1 containing the various mutations was ligated into pTP68 (Henchoz et al. 1997) to express fusions to the GFP (Heim et al. 1995), into pBM18 for expression from the endogenous FAR1 promoter, and pTP62 (Henchoz et al. 1997) for expression from the inducible
$G A L$ promoter. For two-hybrid analysis FAR1 fragments were amplified by PCR, digested with NcoI and XhoI and subcloned into the two-hybrid vectors pEG203 or pJG4-6 as described previously (Butty et al. 1998). pEG203 and pJG4-6 are derivatives of pEG202 and pJG4-5, respectively (Gyuris et al. 1993), with an altered polylinker. The fragment encoding the Msn5p/Ste21pbinding domain of Farlp (amino acids 289-389) was amplified with specific primers introducing HindIII and XhoI restriction sites and ligated to a fragment encoding GFP in frame with the nuclear localization signal of Pho4p (Kaffmann et al. 1998a). The resulting fragment was then ligated into pRS416(ADH), resulting into plasmid pNP124. This plasmid allows expression of a PHO4(NLS)-GFP-NES(289-389) fusion protein from the constitutive $A D H$ promoter. STE21 was amplified by PCR, digested with XhoI and ApaI or SalI and ligated into pEG203 (pBM41) for two-hybrid analysis, or pRS414(G) for expression from the inducible GAL promoter (pBM43). To introduce multiple copies of the 9E10 (myc) epitope at the amino terminus of Msn5p/Ste21p, the BamHI site in MSN5/STE21 was eliminated with a silent mutation, replaced with a new BamHI site at the ATG start codon and ligated with a myc3 cassette flanked by BamHI sites. pLH132 contains one copy, whereas pLH133 contains several copies of the myc cassette. The NotI-XhoI fragment from pLH132 or pLH133 was also cloned into pRS316 (Sikorski and Hieter 1989) yielding plasmid pLH287 and pRS424 yielding plasmids pBM55 and pBM56. The plasmid allowing expression of Msn5p/Ste21p-GFP was constructed as follows: the NotI-XhoI fragment from pLH133 was ligated into pRS316 to yield pLH287; pLH287 was then digested with BamHI to remove the myc3 cassette and replaced with a GFP fragment isolated from pPP356 (Pryciak and Huntress 1998), to yield plasmid pLH266. Both pLH133 and pLH266 are fully functional and able to complement the mating defect of cells deleted for MSN5/STE21 (data not shown).

\section{Antibodies and Western blots}

Standard procedures were used for yeast cell extract preparation and immuno blotting (Brown et al. 1997; Harlow and Lane 1988). Polyclonal anti-Farlp antibodies have been described previously (Henchoz et al. 1997) and 9E10 antibodies were obtained from the ISREC antibody facility. Antibodies specific for actin 
Table 4. Plasmids list

\begin{tabular}{|c|c|c|}
\hline Plasmids & Relevant characteristics & Source \\
\hline pTP68 & GAL FAR1wt-GFP URA3 CEN & Henchoz et al. (1997) \\
\hline рТР487 & GAL Far1 $\Delta 50-$ GFP URA3 CEN & this study \\
\hline pBM9 & GAL Far1-NLS1-GFP URA3 CEN & this study \\
\hline pBM10 & GAL Far1-NLS2-GFP URA3 CEN & this study \\
\hline pBM11 & GAL Far1-NLS1/2-GFP URA3 CEN & this study \\
\hline pTP88 & GAL Far1 ${ }^{1-50}$-GFP URA3 CEN & this study \\
\hline рТР419 & GAL GFP URA3 CEN & this study \\
\hline pmsn5-D3 & Ste21::HIS3 & this study \\
\hline pBM45 & STE21wt LEU2 CEN & this study \\
\hline pBM43 & GAL STE21wt TRP1 CEN & this study \\
\hline pLH287 & STE21-myc ${ }^{\mathrm{n}}$ URA3 CEN & this study \\
\hline pSL2270 & Ste7::ADE2 & Printen and Sprague (1994) \\
\hline pBM41 & pLG203 STE21wt & this study \\
\hline ACB412 & pJG4-6 FAR1wt & Butty et al. (1998) \\
\hline ACB418 & pJG4-6 Far1 ${ }^{353-830}$ & Butty et al. (1998) \\
\hline ACB413 & pJG4-6 Far1 $1^{1-389}$ & Butty et al. (1998) \\
\hline ACB415 & pJG4-6 Far1 $1^{174-285}$ & Butty et al. (1998) \\
\hline pBC100 & pJG4-6 Far1 ${ }^{89-389}$ & this study \\
\hline pBC101 & pJG4-6 Far1 ${ }^{189-389}$ & this study \\
\hline $\mathrm{pBC} 102$ & pJG4-6 Far1 $289-389$ & this study \\
\hline pTP577 & pJG4-6 Far1 $\Delta 285-390$ & this study \\
\hline GA2162 & pJG4-6 Far1 A26 A87 A114 A324 V341 A346 & this study \\
\hline GA2163 & pJG4-6 Far1 A26 A87 A114 A306 V341 A346 & this study \\
\hline pLH132 & STE21-Myc ${ }^{3}$ TRP1 $2 \mu$ & this study \\
\hline pLH133 & STE21-Myc ${ }^{\mathrm{n}}$ TRP1 $2 \mu$ & this study \\
\hline pLH58 & STE21wt URA3 CEN & this study \\
\hline pLH64 & STE21::TRP1 LEU2 $2 \mu$ & this study \\
\hline pBM56 & STE21-Myc ${ }^{\mathrm{n}}$ TRP1 $2 \mu$ & this study \\
\hline pBM55 & STE21-Myc ${ }^{3}$ TRP1 $2 \mu$ & this study \\
\hline ACB435 & GAL FAR1wt LEU2 CEN & Butty et al. (1998) \\
\hline pSH125 & GAL Gsp1 (G21V) URA3 integrative & this study \\
\hline pLH266 & STE21wt-GFP URA3 CEN & this study \\
\hline pTP62 & GAL FAR1wt URA3 CEN & Henchoz et al. (1997) \\
\hline pBM5 & GAL Far1 NLS1 URA3 CEN & this study \\
\hline pBM8 & GAL Far1 NLS1/2 URA3 CEN & this study \\
\hline pTP63 & GAL Far1-22 URA3 CEN & Henchoz et al. (1997) \\
\hline pBM14 & GAL Far1 NLS1/22 URA3 CEN & this study \\
\hline pBM18 & FAR1wt URA3 CEN & this study \\
\hline pBM19 & Far1-22 URA3 CEN & this study \\
\hline pBM20 & Far1-NLS1 URA3 CEN & this study \\
\hline pBM29 & Far1-NLS1/22 URA3 CEN & this study \\
\hline pLH59 & STE21wt URA3 $2 \mu$ & this study \\
\hline pBM58 & GAL Far1 $1285-308$ GFP URA3 CEN & this study \\
\hline pBM76 & GAL Far1 $\Delta 312-382$ GFP URA3 CEN & this study \\
\hline pBM77 & GAL Far1 $1338-382$ GFP URA3 CEN & this study \\
\hline pBM78 & GAL Far1 $\Delta 312-338$ GFP URA3 CEN & this study \\
\hline pBM79 & Far1 $1312-382$ URA3 CEN & this study \\
\hline pBM80 & Far1 $\Delta 338-382$ URA3 CEN & this study \\
\hline pBM81 & Far1 $\Delta 312-338$ URA3 CEN & this study \\
\hline pTP595 & pJG4-6 Far1 $\Delta 312-382$ & this study \\
\hline pTP596 & pJG4-6 Far1 $\Delta 338-382$ & this study \\
\hline pTP597 & pJG4-6 Farl $\Delta 312-338$ & this study \\
\hline pТР598 & pJG4-6 Far1 $\Delta 304-308$ & this study \\
\hline pNP124 & ADH Pho4(NLS)-GFP-Far1(NES) URA3 CEN & this study \\
\hline pTP594 & ADH Pho4(NLS)-GFP URA3 CEN & this study \\
\hline EB0806 & pT7-Myc-GSP1 & Kaffmann et al. (1998b) \\
\hline
\end{tabular}

were purchased from Boehringer Mannheim and used as recommended by the manufacturer.

Coimmunoprecipitation and in vitro binding experiments

Wild-type (K699) or gsp1-1 cells (YSH80) were transformed with a multicopy plasmid expressing myc-tagged Msn5p/Ste21p from the endogenous promoter (pBM56 or pBM55) or for control an empty vector (pRS424) and a plasmid expressing Farlp from the inducible GAL promoter (ACB435; Butty et al. 1998). Cells were grown in selective media containing raffinose $(2 \%$ final 
concentration) to early log phase, at which time galactose $(2 \%$ final concentration) was added for $6 \mathrm{hr}$ at $30^{\circ} \mathrm{C}\left(25^{\circ} \mathrm{C}\right.$ for experiments with gsp1-1 cells followed by a shift at $35^{\circ} \mathrm{C}$ for $3 \mathrm{hr}$ ) to induce expression of Farlp. Cells were pelleted, resuspended in RIPA buffer [50 mm Tris (pH 7.5), $50 \mathrm{~mm} \mathrm{NaCl}, 1 \%$ NP-40, $0.5 \%$ deoxycholate, $0.1 \%$ SDS] containing the protease inhibitors PMSF, aprotinin, leupeptin, and pepstatin (Complete, Boehringer Mannheim), and lysed with a one-shot cell disruptor (Constant Systems Ltd.) set to the maximum pressure (2.8 kBar). The soluble extract was then incubated for $2 \mathrm{hr}$ at $4^{\circ} \mathrm{C}$ with 9E10 monoclonal antibodies and Sepharose beads coupled to protein G (Pharmacia). The beads were washed four times with RIPA buffer, bound proteins eluted with gel-sample buffer, and subjected to immunoblot analysis with polyclonal antibodies against Farlp and 9E10 antibodies to control for the presence of myc-tagged Msn5p/Ste21p.

In vitro binding assays were carried out as follows: GsplpMyc was immunoprecipitated with 9E10 antibodies from extracts prepared from DH5 $\alpha$ cells containing the pT7-MycGsp1 expression plasmid (EB0806). The immunoprecipitate was divided; One-half was incubated for $2 \mathrm{hr}$ at $4^{\circ} \mathrm{C}$ with $2 \mathrm{mM}$ GTP $\gamma$; the other half with $2 \mathrm{~mm}$ GDP in $10 \mathrm{~mm}$ Tris- $\mathrm{HCl}(\mathrm{pH} 7.5)$ containing $20 \mathrm{~mm}$ EDTA and $2 \mathrm{~mm}$ DTT. The reaction was stopped by adding $\mathrm{MgCl}_{2}$ to a final concentration of $50 \mathrm{~mm}$.

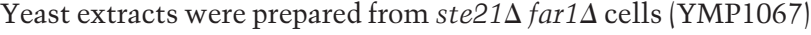
transformed with control vectors, or plasmids expressing Farlp (CMP62; Henchoz et al. 1997) and Msn5p/Ste21p (pBM43) from the inducible $G A L$ promoter. Cells were grown at $30^{\circ} \mathrm{C}$ to early log phase in selective media containing raffinose ( $2 \%$ final concentration), at which time galactose ( $2 \%$ final concentration) was added for $6 \mathrm{hr}$. Cells were lysed in phosphate-buffered saline [PBS: $137 \mathrm{~mm} \mathrm{NaCl}, 2.7 \mathrm{~mm} \mathrm{KCl}, 4.3 \mathrm{~mm} \mathrm{Na}_{2} \mathrm{HPO}_{4}-7 \mathrm{H}_{2} \mathrm{O}, 1.4$ $\mathrm{mM} \mathrm{KH} \mathrm{PO}_{4}(\mathrm{pH}$ 7.3)] containing the protease inhibitors PMSF, aprotinin, leupeptin, and pepstatin (Complete, Boehringer Mannheim) as described above and the extracts incubated for 2 $\mathrm{hr}$ at $4^{\circ} \mathrm{C}$ with Gsplp-Myc-containing beads. The beads were washed four times with PBS, bound proteins eluted with gelsample buffer, and analyzed by immunoblotting as described.

\section{Two-hybrid assays}

Two-hybrid assays were performed as described (Brown et al. 1997) in EGY48- or W303-based yeast strains using pEG202based plasmids expressing LexA DNA-binding domain fusions (DBD), and pJG4-5-based plasmids containing fusions to the B42 transcriptional activation domain (AD) (Gyuris et al. 1993). Miller units are averages of at least six independent experiments (with independent colonies) with standard deviations. For experiments with pheromones, cells were grown in selective media containing galactose ( $2 \%$ final concentration) to early log phase, at which time the culture was divided and pheromone $(25 \mu \mathrm{g} / \mathrm{ml}$ final concentration) was added to one half. After the times indicated, an aliquot was analyzed as described above. The values were expressed as percent Miller units compared to wild-type controls grown in the absence of pheromones; each time point represents the average of at least four independent experiments (with independent colonies).

\section{Microscopy and budding assays}

Yeast actin was visualized with rhodamine-phalloidin (Molecular Probes, Inc., Leiden, The Nctherlands). Briefly, cells were fixed with formaldehyde (3.7\% final concentration) for $60 \mathrm{~min}$, washed and stained for $20 \mathrm{~min}$ on ice with rhodamine-phalloidin (diluted 1:5 in methanol), washed three times with PBS, and viewed on a Zeiss Axiophot fluorescence microscope. At least
200 cells were counted for the morphological analysis. Proteins tagged with GFP were visualized using a Chroma GFPII filter (excitation 440-470 nm), photographed with a Photometrics CCD camera, and analyzed with Photoshop 4.0 software (Adobe). Photographs shown are overlays of phase contrast and fluorescence images. Cells expressing Farlp-GFP from the inducible $G A L$ promoter were grown to early $\log$ phase at $25^{\circ} \mathrm{C}$ in selective media containing raffinose ( $2 \%$ final concentration), at which time galactose was added ( $2 \%$ final concentration) for 6 $\mathrm{hr}$. Where indicated $\alpha$-factor $(25 \mu \mathrm{g} / \mathrm{ml}$ final concentration) was added during the last $3 \mathrm{hr}$. LH90 cells expressing Msn5p/ Ste21p-GFP from the endogenous promoter (pLH58) were grown in selective media at $30^{\circ} \mathrm{C}$ to early log phase. Where indicated $\alpha$-factor $(25 \mu \mathrm{g} / \mathrm{ml}$ final concentration) was added for $2 \mathrm{hr}$.

The budding pattern of cells overexpressing wild-type or cytoplasmic mutant forms of Farlp was determined after staining bud scars with calcofluor as described (Guthrie and Fink 1991). Briefly, cells were grown in selective media containing raffinose ( $2 \%$ final concentration) to early log phase, at which time galactose ( $2 \%$ final concentration) was added; cells were kept in $\log$ phase for $36 \mathrm{hr}$ by successive dilutions. Cells were stained with calcofluor and counted on a Zeiss Axiophot fluorescence microscope using a UV filter. Only cells with more than three bud scars were included in the analysis.

\section{Acknowledgments}

We thank members of the laboratory for helpful discussions, $\mathrm{M}$. Funk, P. Pryciak, E. Elion, E. O'Shea, B. Catarin, E. Schwob, A.-C. Butty, F. van Drogen, and M. Tsai for plasmids and strains. K. Hoffmann kindly provided a detailed alignment of Msn5p/ Ste21p with importins/exportins. S. Henchoz is acknowledged for help during early aspects of this work, T. Laroche and A. de Bruyn Kops for advice with the microscope, J.-M. Galan and A.-C. Butty for help with coimmunoprecipitation and budding pattern experiments, N. Perrinjaquet for excellent technical assistance, and B. Amati, V. Simanis, and R. Iggo for critical reading of the manuscript. M.B. is supported by Association pour La Recherche sur le Cancer (ARC) and an European Molecular Biology Organization (EMBO) long-term fellowship, and L.S.H. by an NIH and a Herbert W. Boyer postdoctoral fellowship. M.P. is supported by the Swiss National Science Foundation, the Swiss Cancer League, and a Helmut Horten Incentive award.

The publication costs of this article were defrayed in part by payment of page charges. This article must therefore be hereby marked 'advertisement' in accordance with 18 USC section 1734 solely to indicate this fact.

\section{References}

Akada, R., L. Kallal, D.I. Johnson, and J. Kurjan. 1996. Genetic relationships between the G-protein beta gamma complex, Ste5p, Ste20p and Cdc42p: Investigation of effector roles in the yeast pheromone response pathway. Genetics 143: 103117.

Alepuz, P.M., D. Matheos, K.W. Cunningham, and F. Estruch. 1999. The Saccharomyces cerevisiae RanGTP binding protein Msn5p is involved in different signal transduction pathways. Genetics (in press).

Arkowitz, R.A. 1999. Responding to attraction: Chemotaxis and chemotropism in Dictyostelium and yeast. Trends Cell Biol. 9: 20-27.

Ausubel, F.M., R. Brent, R.E. Kingston, D.D. Moore, J.G. 
Seidman, J.A. Smith, and K. Struhl. 1991. Current protocols in molecular biology. Greene Publishing Associates and Wiley-Interscience, New York, NY.

Bähler, J. and M. Peter. 1999. Cell polarity in yeast. In Frontiers in molecular biology: cell polarity (ed. D.G. Drubin), Oxford University Press (In press).

Beals, C.R., N.A. Clipstone, S.N. Ho, and G.R. Crabtree. 1997. Nuclear localization of NF-ATc by a calcineurin-dependent, cyclosporin-sensitive intramolecular interaction. Genes \& Dev. 11: 824-834.

Brown, J.L., M. Jaquenoud, M.P. Gulli, J. Chant, and M. Peter. 1997. Novel Cdc42-binding proteins Gic1 and Gic2 control cell polarity in yeast. Genes \& Dev. 11: 2972-2982.

Butty, A.-C., P. Pryciak, L. Huang, I. Herskowitz, and M. Peter. 1998. The role of Farlp in linking the heterotrimeric G-protein to polarity establishment proteins during yeast mating. Science 282: 1511-1516.

Chang, F. and I. Herskowitz. 1990. Identification of a gene necessary for cell cycle arrest by a negative growth factor of yeast: FAR1 is an inhibitor of a G1 cyclin, CLN2. Cell 63: 999-1011.

Chant, J. 1996. Generation of cell polarity in yeast. Curr. Opin. Cell Biol. 8: 557-565.

Cook, J.G., L. Bardwell, S.J. Kron, and J. Thorner. 1996. Two novel targets of the MAP kinase Kss1 are negative regulators of invasive growth in the yeast Saccharomyces cerevisiae. Genes \& Dev. 10: 2831-2848.

De Vit, M.J., J.A. Waddle, and M. Johnston. 1997. Regulated nuclear translocation of the Migl glucose repressor. Mol. Biol. Cell 8: 1603-1618.

Dingwall, C. and R.A. Laskey. 1991. Nuclear targeting sequences-A consensus? Trends Biochem. Sci. 16: 478-481.

Dorer, R., P.M. Pryciak, and L.H. Harwell. 1995. Saccharomyces cerevisiae cells execute a default pathway to select a mate in the absence of pheromone gradients. I. Cell Biol. 131: 845-861.

Feldherr, C.M. and D. Akin. 1994. Role of nuclear trafficking in regulating cellular activity. Int. Rev. Cytol. 151: 183-228.

Elion, E.A., P.L. Grisafi, and G.R. Fink. 1990. FUS3 encodes a cdc2+/CDC28-related kinase required for the transition from mitosis into conjugation. Cell 60: 649-664.

Gartner, A., A. Jovanovic, D.I. Jeoung, S. Bourlat, F.R. Cross, and G. Ammerer. 1998. Pheromone-dependent $\mathrm{G}_{1}$ cell cycle arrest requires Farl phosphorylation, but may not involve inhibition of Cdc28-Cln kinase, in vivo. Mol. Cell Biol. 18: 3681-3691.

Göhrlich, D. and I. Mattaj. 1996. Nucleocytoplasmic transport. Science 271: 1513-1518.

Göhrlich, D., N. Pante, U. Kutay, U. Aebi, and F.R. Bischoff. 1996. Identification of different roles for RanGDP and RanGTP in nuclear protein import. EMBO J. 15: 5584-5594.

Göhrlich, D., M. Dabrowski, F.R. Bischoff, U. Kutay, P. Bork, E. Hartmann, S. Prehn, and E. Izaurralde. 1997. A novel class of RanGTP binding proteins. J. Cell Biol. 14: 65-80.

Gorner, W., E. Durchschlag, M.T. Martinez-Pastor, F. Estruch, G. Ammerer, B. Hamilton, H. Ruis, and C. Schuller. 1998. Nuclear localization of the $\mathrm{C} 2 \mathrm{H} 2$ zinc finger protein $\mathrm{Msn} 2 \mathrm{p}$ is regulated by stress and protein kinase A activity. Genes \& Dev. 12: 586-597.

Grishin, A.V., M. Rothenberg, M.A. Downs, and K.J. Blumer. 1998. Mot3, a Zn finger transcription factor that modulates gene expression and attenuates mating pheromone signaling in Saccharomyces cerevisiae. Genetics 149: 879-892.

Guthrie, C. and G.R. Fink. 1991. Guide to yeast genetics and molecular biology. Academic Press, San Diego, CA.

Gyuris, J., E. Golemis, H. Chertkov, and R. Brent. 1993. Cdi, a human G1 and S phase protein phosphatase that associates with Cdk2. Cell 75: 791-803.

Harlow, E. and D. Lane. 1988. Antibodies: A laboratory manual. Cold Spring Harbor Laboratory, Cold Spring Harbor, NY.

Heim, R., A.B. Cubitt, and R.Y. Tsien. 1995. Improved green fluorescence. Nature 373: 663-664.

Henchoz, S., Y. Chi, B. Catarin, I. Herskowitz, R.J. Deshaies, and M. Peter. 1997. Phosphorylation- and ubiquitin-dependent degradation of the cyclin-dependent kinase inhibitor Farlp in budding yeast. Genes \& Dev. 11: 3046-3060.

Herskowitz, I. 1995. MAP kinase pathways in yeast: For mating and more. Cell 80: 187-197.

Hood, J.K. and P.A. Silver. 1999. In or out? Regulating nuclear transposrt. Curr. Opin. Cell Biol. 11: 241-247.

Ito, H., Y. Fukuda, K. Murata, and A. Kimura. 1983. Transformation of intact yeast cells treated with alkali cations. $J$. Bacteriol. 153 163-168.

Izauralde, E., U. Kutay, C. von Kobbe, I.W. Mattaj, and D. Göhrlich. 1997. The asymmetric distribution of the constituents of the Ran system is essential for transport in and out of the nucleus. EMBO J. 16: 6535-6547.

Kaffmann, A. and E.K. O'Shea. 1999. Regulation of nuclear localization: A key to a door. Annu. Rev. Cell Dev. Biol. (in press).

Kaffmann, A., N. Miller Rank, and E.K. O'Shea. 1998a. Phosphorylation regulates association of the transcription factor Pho4p with its import receptor Pse1/Kap121. Genes \& Dev. 12: 2673-2683.

Kaffmann, A., N. Miller Rank, E.M. O'Neill, L.S. Huang, and E.K. O'Shea. 1998b. Msn5 is a nuclear export receptor for the phosphorylated transcription factor Pho4. Nature 396: 482486.

Kalderon, D., W.D. Richardson, A.F. Markham, and A.E. Smith. 1984. Sequence requirements for nuclear location of simian virus 40 large-T antigen. Nature 311: 33-38.

Koepp, D. and P.A. Silver. 1996. A GTPase controlling nuclear trafficking: Running the right way or walking RANdomly? Cell 87: 1-4.

Kranz, J.E., B. Satterberg, and E.A. Elion. 1994. The MAP kinase Fus3 associates with and phosphorylates the upstream signaling component Ste5. Genes \& Dev. 8: 313-327.

Leeuw, T., C. Wu, J.D. Schrag, M. Whiteway, D.Y. Thomas, and E. Leberer. 1998. Interaction of a G-protein beta subunit with a conserved sequence in Ste20/PAK family protein kinases. Nature 391 191-195.

Leberer, E., D.Y. Thomas, and M. Whiteway. 1997. Pheromone signalling and polarized morphogenesis in yeast. Curr. Opin. Genet. Dev. 7: 59-66.

Longtine, M.S., A. McKenzie, D.J. Demarini, N.G. Shah, A. Wach, A. Brachat, P. Philippsen, and J.R. Pringle. 1998. Additional modules for versatile and economical PCR-based gene deletion and modification in Saccharomyces cerevisiae. Yeast 10: 953-961.

Martinez-Pastor, M. T., G. Marchler, C. Schuler, A. MarchlerBauer, H. Ruis, and F. Estruch. 1996. The Saccharomyces cerevisiae zinc finger proteins Msn2p and Msn4p are required for transcriptional induction through the stressresponse element (STRE). EMBO I. 15: 2227-2235.

McKinney, J.D. and F.R. Cross. 1995. FAR1 and the $G_{1}$ phase specificity of cell cycle arrest by mating factor in Saccharomyces cerevisiae. Mol. Cell Biol. 15: 2509-2516.

Moll, T., G. Tebb, U. Surano, H. Robitsch, and K. Nasmyth. 1991. The role of phosphorylation and the CDC28 protein kinase in cell cycle-regulated nuclear import of the S. cerevisiae transcription factor SWI5. Cell 66: 743-758. 
Nakielny, S. and G. Dreyfuss. 1997. Nuclear export of proteins and RNAs. Curr. Opin. Cell Biol. 9: 420-429.

Nern, A. and R.A. Arkowitz. 1999. A Cdc24p-Farlp-Gbetagamma protein complex required for yeast orientation during mating. J. Cell Biol. 144: 1187-1202.

Nigg, E.A. 1997. Nucleocytoplasmic transport: Signals, mechanisms and regulation. Nature 386: 779-787.

Oehlen, L.J., J.D. McKinney, and F.R. Cross. 1996. Ste12 and $\mathrm{Mcm} 1$ regulate cell cycle-dependent transcription of FAR1. Mol. Cell. Biol. 16: 2830-2837.

Peter, M. and I. Herskowitz. 1994. Direct inhibition of the yeast cyclin-dependent kinase Cdc28-Cln by Far1. Science 265: 1228-1231.

Peter, M., A. Gartner, J. Horecka, G. Ammerer, and I. Herskowitz. 1993. FAR1 links the signal transduction pathway to the cell cycle machinery in yeast. Cell 73: 747-760.

$\mathrm{Pi}, \mathrm{H} ., \mathrm{C} . \mathrm{T}$. Chien, and S. Fields. 1997. Transcriptional activation upon pheromone stimulation mediated by a small domain of Saccharomyces cerevisiae Ste12p. Mol. Cell. Biol. 17: 6410-6418.

Pinten, J.A. and G.F. Sprague. 1994. Protein-protein interactions in the yeast pheromone response pathway: Ste $5 p$ interacts with all members of the MAP kinase cascade. Genetics 138: 609-619.

Pryciak, P.M. and F.A. Huntress. 1998. Membrane recruitment of the kinase cascade scaffold protein Ste5 by the G $\beta \gamma$ complex underlies activation of the yeast pheromone response pathway. Genes \& Dev. 12: 2684-2697.

Rout, M.P., G. Blobel, and J.D. Aitchison. 1997. A distinct nuclear import pathway used by ribosomal proteins. Cell 89: 715-725.

Sambrook, J., E.F. Fritsch, and T. Maniatis. 1989. Molecular cloning: A laboratory manual. Cold Spring Harbor Laboratory Press, Cold Spring Harbor, NY.

Schlenstedt, G., E. Smirnova, R. Deane, J. Solsbacher, U. Kutay, D. Görlich, H. Ponstingl, and F.R. Bischoff. 1997. Yrb4, a yeast ran-GTP-binding protein involved in import of ribosomal protein L25 into the nucleus. EMBO J. 16: 6237-6249.

Sidorova, J.M., G.E. Miskesell, and L.L. Breeden. 1995. Cell cycle-regulated phosphorylation of Swi6 controls its nuclear localization. Mol. Biol. Cell 6: 1641-1658.

Sikorski, R.S. and P. Hieter. 1989. A system of shuttle vectors and yeast host strains designed for efficient manipulation of DNA in Saccharomyces cerevisiae. Genetics 122: 19-27.

Sprague, G.F. and J.W. Thorner. 1992. Pheromone response and signal transduction during the mating process of Saccharomyces cerevisiae. In The molecular and cellular biology of the yeast Saccharomyces (ed. E.W. Jones, J.R. Pringle, and J.R. Broach), pp.657-744. Cold Spring Harbor Laboratory Press, Cold Spring Harbor, NY.

Tedford, K., S. Kim, D. Sa, K. Stevens, and M. Tyers. 1997. Regulation of mating pheromone and invasive growth responses in yeast by two MAP kinase substrates. Curr. Biol. 7: $228-238$

Tyers, M. and B. Futcher. 1993. Far1 and Fus3 link the mating pheromone signal transduction pathway to three $G_{1}$-phase Cdc28 kinase complexes. Mol. Cell. Biol. 13: 5659-5669.

Valtz, N. and M. Peter. 1997. Functional analysis of FAR1 in yeast. Methods Enzymol. 283: 350-365.

Valtz, N., M. Peter, and I. Herskowitz. 1995. FAR1 is required for oriented polarization of yeast cells in response to mating pheromones. J. Cell Biol. 131: 863-873.

Weis, K. 1998. Importins and exportins: How to get in and out of the nucleus. Trends Biochem. Sci. 23: 185-189. 


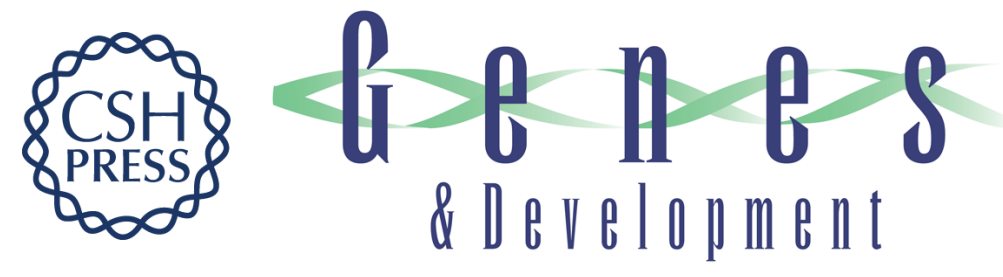

\section{Nuclear export of Far1p in response to pheromones requires the export receptor Msn5p/Ste21p}

Marc Blondel, Paula M. Alepuz, Linda S. Huang, et al.

Genes Dev. 1999, 13:

References This article cites 53 articles, 28 of which can be accessed free at:

http://genesdev.cshlp.org/content/13/17/2284.full.html\#ref-list-1

License

Email Alerting

Receive free email alerts when new articles cite this article - sign up in the box at the top

Service right corner of the article or click here.

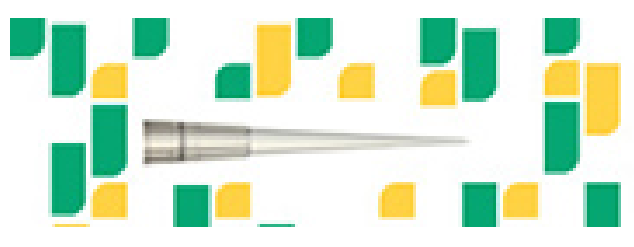

Focused on your science. 